\title{
«EL DIABLO VESTIDO DE FRAILE»: CORRESPONDENCIA ENTRE EL PADRE ANTONIO SOLER Y UN NOBLE ESPAÑOL (1761-1773)*
}

\author{
George Truett HolLis
}

\begin{abstract}
On 16 March 1761 Padre Antonio Soler wrote a letter to the Duke of Medina Sidonia asking politely for the return of a gift of a «Book of Harpsichord Music. Thus began a twelve-year correspondence between Soler ( 22 letters) and the duke. Central to the correspondence was the young Catalan harpsichordist, Pedro Santamant (b. 1752), who was in the service of the duke («I have seen him perform wonders on the harpsichord»). At the duke's request, Soler agreed to teach Santamant composition at El Escorial. The correspondence ended with Soler angrily demanding the return of some sonatas from «a Book of 40 Sonatas.»

The correspondence gives us a «glimpse of Soler's personal and musical character.» In addition to providing new data for Soler's biography, it reveals the didactic purpose for some of his sonatas, as well as information on eighteenth-century Spanish harpsichords. Perhaps it will also give us a better understanding of Soler's music.
\end{abstract}

\section{Resumen}

El 16 de marzo de 1761, el Padre Antonio Soler escribió una carta al Duque de Medina Sidonia, pidiendo con cortesía, la vuelta de un regalo del «Libro de Clavicordio». Así comenzó una correspondencia de doce años entre Soler (22 cartas) y el duque. El centro de la correspondencia era el joven clavicordista de Cataluña, Pedro Santamant (n. 1752), el cual en 1765 estaba al servicio del duque («lo he visto ejecutar maravillas en al clabe»). A solicitud del duque, Soler consintió enseñar composición a Santamant en El Escorial. La correspondencia terminó con cólera por parte de Soler demandando la vuelta de algunas sonatas de un «Lib" de 40 Sonatas».

La correspondencia «nos permite vislumbrar el carácter personal y musical» de Soler. Además, ofrece nueva información para la biografía de Soler. Revela el carácter didáctico de algunas sonatas de Soler, así como más información sobre el clavicordio español del siglo XVIII. Quizás nos permitirá también comprender mejor la música de Soler.

Los informes biográficos que existen acerca del padre Antonio Soler, el más famoso músico español del siglo XVIII, emanan principalmente de su necrología en las Memorias sepul-

* Este artículo está dedicado a la memoria de mi esposa, la Dra. Eleanor Russell (1931-1993), colaboradora del Anuario Musical (1974) en reconocimiento de sus contribuciones a la musicología española del siglo XVI.

Otra versión de este artículo en inglés, más corta y sin los textos españoles de las cartas, fue publicada por Cambridge University Press en Music in Spain during the Eighteenth century, capítulo XIII (1998).

Doy gracias a la Excma. Duquesa de Medina Sidonia por su generosidad al permitirme la consulta de su archivo particular a mi esposa y a mí, y por su hospitalidad y su interés en mi obra.

Doy gracias también a Jason Bargueño por traducir mi artículo al castellano. La ortografía, la capitalización y la puntuación de las cartas han sido conservadas. La fórmula de la conclusión de las cartas ha sido conservada solamente en la primera carta de Soler.

Anuario Musical, 54 (1999) 
crales y en las Actas capitulares del monasterio jerónimo de San Lorenzo el Real de El Escorial. ${ }^{1}$ Nacido en 1729 en Olot, Soler fue educado musicalmente en la Escolanía del monasterio de Montserrat. Llegó a El Escorial desde Lérida como organista y novicio en septiembre de 1752 y tomó sus votos perpetuos un año después. En 1754 obtuvo del monasterio una pensión de 100 ducados anuales para su padre, músico militar jubilado. El padre Soler llegó a ser maestro de capilla en El Escorial después del 25 de noviembre de 1758 (la fecha de la muerte del maestro de capilla padre Gabriel de Moratilla) y en 1762 publicó un tratado teórico, Llave de la modulación y antigüedades de la música, que fue financiado por la comunidad monástica. En el otoño de 1768, cuando vino la Corte a El Escorial, «mereció dar lección de clave al Serenísimo Sr. Infante D. Gabriel» y para él compuso bastantes obras y construyó un instrumento demostrando las divisiones del tono. Por este trabajo le daba Don Gabriel cada año 25 doblones. El padre Soler murió el 20 de diciembre de 1783.

Acerca de las características personales de Soler, el escritor anónimo de las Memorias sepulcrales alabó su «buen porte y proceder» durante su año de aprobación y su «mucha aplicación a su estudio del órgano y composición, a lo que era incansable, así no salía a campo ni a diversión alguna.»El padre Soler es ensalzado por ser extremadamente devoto, «amante de la celda», rápido en sus movimientos, de poco dormir y confesando frecuentemente «con muchos sollozos, suspiros y lágrimas, pues tenía un genio muy compasivo y tierno.» Reforzando esta imagen del fraile piadoso está la necrología que el propio Soler escribió sobre fray Pedro Serra, condiscípulo suyo en Montserrat y músico de El Escorial, en marzo de 1766 [Memorias sepulcrales, ff. 401v-405v].

Sólo siete cartas escritas por el padre Soler eran conocidas hasta ahora. ${ }^{2}$ Dirigidas al padre Giambattista Martini de Bologna en un italiano rudimentario aportan algunos detalles sobre las actividades musicales de Soler pero son destinadas, evidentemente, a ganarse el favor de Martini con la esperanza de obtener su apoyo para el «tratado» de Soler, por entonces bajo crítica. ${ }^{3}$ Las respuestas de Martini no han sido halladas.

Eruditos del siglo Xx encuentran una gran discrepancia entre la imagen del fraile piadoso de El Escorial y el compositor de las sonatas para teclado de Soler, de los quintetos y conciertos para dos teclados. Ralph Kirkpatrick comentó en su estudio de Domenico Scarlatti en 1953:

Tan extraño como era encontrar a Domenico Scarlatti sólo en ese edificio tan solemne y grandioso [El Escorial], las sonatas y quintetos que salieron de las manos monásticas de Soler eran aún más extraños. No se podía imaginar nada más alegre ni más frívolo. ${ }^{4}$

1. Microfilm del original en Archivo del Palacio de Oriente; copia en Biblioteca Nacional (Madrid), Fondo Barbieri, Ms. 14.084 ${ }^{678-689}$, publicado en Rubio, SAmuel: Antonio Soler / Catálogo Crítico (Cuenca, 1980), págs. 12-14 y 17-19.

2. KAstner, Santiago: «Algunas cartas del P. Antonio Soler dirigidas al P. Giambattista Martini», Anuario Musical, 12 (1957), págs. 235-241.

3. Pagano, Roberto: Alessandro e Domenico Scarlatti: due vite in una (Milano, 1985), pág. 436. «Le polemiche sollevate dall'opera indussero Soler a cercare l'appoggio autorevolissimo del padre Martini, anche per dare soddisfazione ai suoi confratelli, che di buon grado avevano sopportato le spese di stampa della Llave.»'

4. KirkPatrick, Ralph: Domenico Scarlatti (Princeton, 1953; New York, 1968), pág. 123: «Strange as it was to find Domenico Scarlatti himself at that solemn and ponderous edifice [El Escorial], the sonatas and quintets that emerged under Soler's monastic hands were even stranger. Anything gayer and more frivolous could hardly be imagined.» 
Klaus Heimes, en su tesis de 1965 sobre las sonatas para teclado de Soler, lamentó que «los pocos detalles sobre la vida de Soler no nos permiten vislumbrar su carácter personal y musical.» Heimes finaliza diciendo: «Pero esta imagen [...] dibujada con tanto amor y respeto por el cronista anónimo [en las Memorias sepulcrales] es incompleta.» ${ }^{5}$

Este ensayo, basado en correspondencia entre el padre Soler y un noble español que acudía a la corte en los sitios reales, incluyendo El Escorial cada otoño, nos permitirá vislumbrar el carácter personal y musical de Soler y ayudará a completar la imagen. Quizás nos permitirá también comprender mejor su música y resolver algunos misterios sobre el clavicordio español del siglo XVIII.

Los viajeros ingleses en España durante el siglo XVIII solían incluir una visita al «Convento de San Lorenzo, comúnmente llamado el EsCURIAL.» ${ }^{6}$ Construido por Felipe II en el siglo XVI, El Escorial fue diseñado como una combinación de palacio para el rey, monasterio para unos doscientos monjes jerónimos, e iglesia con un panteón subterráneo para la realeza española, todo con la forma de una parrilla, simbolizando la muerte de San Lorenzo. Localizado a unos $40 \mathrm{~km}$. al norte de Madrid, el viaje, en el siglo XVIII, duraba unas cuatro horas en carruaje. Aquellos viajeros ingleses que más tarde publicaron descripciones del monasterio, como Edward Clarke, Richard Twiss, Henry Swinburne y Joseph Townsend, comentaron desdeñosamente - por lo general- lo que vieron.

Clarke, que visitó El Escorial en 1760, lo describió como «un gran edificio vasto y confuso, dividido en un gran número de patios cuadrados.» ${ }^{7}$ Twiss se lamentó de que «la fachada principal... está vuelta hacia las montañas» en lugar de mirar hacia Madrid y de que la iglesia tenía un interior muy oscuro. ${ }^{8}$ Townsend reportó que «El Escurial, como residencia, no es agradable... expuesta al sol... sin sombra, no tiene ningún atractivo local durante ninguna de las estaciones del año.» ${ }^{9}$ La corte española residía allí cada año, por lo general, desde el 9 de octubre al 10 de diciembre.

Lo único que impresionó a los visitantes ingleses en El Escorial fue la biblioteca, que contenía 22.000 volúmenes, de los cuales eran manuscritos unos 4.300. Clarke observó: «Toda esta riqueza es depositada en las manos de unos cuantos monjes analfabetos, jerónimos pobres, pero celosos de estos tesoros, como si comprendieran su valor verdadero.» ${ }^{10}$

5. HeImes, Klaus: Antonio Soler's Keyboard Sonatas (Pretoria, 1969), pág. 5: «... the few available details about his [Soler's] life do not allow us so much as a glimpse of his personal and musical character, [...] But this picture of Soler's character, drawn so lovingly and respectfully by the nameless chronicler [in the Memorias sepulcrales], is incomplete.»

6. Clarke, Edward: Letters concerning the Spanish Nation, Written at Madrid During the Years 1760 and 1761 (London, 1763), pág. 130: «Description of the Convent of St. Lawrence, commonly called the EsCuRIAL.»

7. ClARKE, pág. 135: «It is a large, confused, stupendous pile, divided into a vast number of square courts.»

8. Twiss, Richard: Travels Through Portugal and Spain in 1772 and 1773 (London, 1775), págs. 100-101: «The chief front $[\ldots]$ is turned towards the mountains, which are only a hundred paces distant; and it is dark there half an hour before it is so at the back front, which commands a fine prospect, that reaches quite to Madrid. [...] The choir is so ill placed, that it renders the church very obscure: here are two hundred and sixteen choral books in folio.».

9. TownsEnd, Joseph: A Journey Through Spain in the Years 1786 and 1787 (London, 1791), pág. 123: «The Escurial, as a residence, is far from pleasant. [...] exposed, as it is, to the full stroke of the meridian sun [...] and destitute of shade, it has no local charms at any season of the year.»

10. Clarke, pág. 134: «All this wealth is deposited in the hands of a few illiterate monks, poor Jero[ny]mites; but they are full as jealous of these treasures, as if they understood their true value.» 
Uno de los nobles españoles que iba a la corte en otoño en El Escorial era Pedro de Alcántara Alonso Pérez de Guzmán, el Bueno, decimocuarto Duque de Medina Sidonia, noble de primera categoría y caballero de la Orden del Toisón de Oro, etc. Estaba casado con la hija de la Duquesa de Alba y hermana del Duque de Huéscar, mayordomo mayor del rey y, después de 1755, duodécimo Duque de Alba. En una carta desde el monasterio de San Lorenzo en octubre de 1753, el joven Duque de Medina Sidonia se quejaba a su esposa que había quedado en Madrid: «Aquí no ay caza ni operas con q. ${ }^{e}$ no se lo q. ${ }^{e}$ nos detiene.» ${ }^{11} \mathrm{Al}$ año siguiente, se quejó más amargamente de:

«... el negro destino de esta jornada, donde me hallo p. ${ }^{\mathrm{r}}$ oblig. ${ }^{\text {on }}$ y sin voluntad en un gran quarto pero sin luz, de modo q. ${ }^{\mathrm{e}}$ pareze uno de los nichos de la Pantheon, con q. ${ }^{\mathrm{e}}$ casi estoy enterrado en vida; ... En q. ${ }^{\text {to }}$ a Frailes estamos iguales, y en quanto â sino unas tambien, solo ay la diferencia de que... yo sufro esto p. $^{\mathrm{r}}$ precision.» ${ }^{12}$

En febrero de 1758 el Duque de Medina Sidonia, de 33 años, fue nombrado caballerizo mayor de la reina María Bárbara. La reina murió en agosto del mismo año y el rey Fernando VI un año después. La corte española no regresó a El Escorial hasta el 30 de septiembre de 1760, para el entierro de la esposa de Carlos III, reina por un año y cuatro días. ${ }^{13}$

Joseph Baretti, uno de los visitantes extranjeros en Madrid durante 1760, escribió sobre el Duque de Medina Sidonia que «tenía fama de ser más ilustrado que cualquiera de los nobles.» Él era la única persona, se decía, que tenía una colección completa de las obras de Lope de Vega. ${ }^{14}$ La correspondencia del duque — durante 1760 - incluía arreglos para la compra de las obras de Voltaire y los poemas de Metastasio, cartas del padre Antonio Eximeno - jesuitaacerca de los libros religiosos, y cartas previniendo al duque sobre Eximeno. Excepto por las cartas familiares, la correspondencia es formal e impersonal. El duque se quejó con confianza a su secretàrio acerca del costo de la reparación de la casa de Madrid «para no vivir en ella en todo el año según la arrastrada vida de esta corte.» ${ }^{15}$

La primera carta del padre Soler al Duque de Medina Sidonia data del 16 de marzo de 1761. Da información acerca de ciertos detalles sobre el propio Soler, sorprendente por su tono personal y atrevido, como Soler reconoció al pedir la devolución de un regalo de música:

11. ADMS (= Archivo de los Duques de Medina Sidonia, archivo particular), Leg. 2322, Duque de Medina Sidonia a la Duquesa, 16 de octubre de 1753.

12. ADMS, Leg. 2325, Duque de Medina Sidonia a la Duquesa, 20 de octubre de 1754.

13. Clarke, págs. 116-117.

14. BARETti, Joseph: A Journey from London to Genoa, Through England, Portugal, Spain, and France (London, 1770), III, pág. 43: «... very difficult to collect all the works of Lope de Vega, though the most popular poet amongst the Spaniards. There is nobody (they say) that has an entire set, but the Duke of Medina Sidonia, who has the reputation of being endowed with a greater share of learning, than any other of the nobles.»

15. ADMS, Leg. 2343, Duque de Medina Sidonia a Santiago Sáez, 7 de agosto de 1760. Más tarde, cuando Eximeno envió al duque «un tratado sobre la música», confió el duque a Sáez: «Yo gusto mas de gozar de la música que de disputar.» (Leg. 2392, 2 de septiembre de 1774) Tocante a Eximeno y su tratado, véase MARTín Moreno, Antonio: Historia de la Música española, 4. Siglo XVIII (Madrid, 1985), págs. 436-437. 
$\ll \mathrm{Ex}^{\mathrm{mo}} \cdot \mathrm{S}^{\mathrm{r}}$

$\mathrm{S}^{\mathrm{r}}$ : por dudár de si V. E. pasara a la jornada de Aranjuez ô nó, me he determinado escrivir esta â V. E. a fin de participarle como tengo animo de pasar â Cataluña a tener mi recreacion, y como mi Maestro tiene tanta gana de vér mis obras, se me haze preciso el llevár el Libro de Clavicordio que entregué â V. E. con muchissimos otros obras mas papeles, y dejarlos copiados para el servicio de $\mathrm{N}^{\text {tra }} \mathrm{S}^{\mathrm{ra}}$ de Monsserrate, de la qual casa salí educado, Espirituál, y Corporalmente. Si V. E. no pasa â Aranjuez podrá guardame el dicho Libro hasta que io en Persona vaia por el, que será mas tardar por primeros del Sige mes, y sino el dador de está es hermo mio carnál, se llama $\mathrm{D}^{\mathrm{n}}$ Matheo Solér, y es musico de los Guardias val·lonas, podrá V. E. entregarle â el, que me le guardara para dicho tiempo. V. E. me perdone el atrevimo ${ }^{\text {to }}$, que a no ser la dicha ocasión, aunque me hiziera falta el dicho libro, nunca tuviera osadia â mentarle.

No ignorará V. E. como Su Mag ${ }^{\underline{d}}$ â nombrado por Prior de Esta Casa al $\mathrm{P}^{\mathrm{e}} \mathrm{M}^{\mathrm{o}}$ Valle quien discurro procurará agradablem ${ }^{\text {te }}$ a desahazér las contiendas pasadas.

Quedo de V. E. siempre seguro Amigo, y deseoso de servirle en lo que mi corta capacidad puede y valga.

$\mathrm{D}^{\underline{s}} \mathrm{~g}^{\mathrm{de}} \hat{\mathrm{a}} \mathrm{V}$. E. los dilatados $\mathrm{a}^{\mathrm{s}}$ de vida le deseo como puede

$S^{\mathrm{n}}$ Lorenzo, y Marzo 16 de 1761

$$
\mathrm{Ex}^{\mathrm{mo}} \mathrm{S}^{\mathrm{r}}
$$

B. L. M. de V. E

Su Capp. ${ }^{\mathrm{n}}$ y Servidor de veras

fr. Antonio Solér H[ieronymite].» ${ }^{16}$

Esta carta muestra, en primer lugar, que una relación cordial pero respetuosa se había establecido con un gran amante de la música. En segundo lugar, confirma que Soler fue de vacaciones al monasterio de Montserrat en 1761, como se declaraba en las Memorias sepulcrales [ff. 403v-404r]. En tercer lugar, nos informa de que para 1760 Soler había compilado ya un «Libro de Clavicordio» y quería llevar copias a su antiguo maestro en Montserrat, con quien había mantenido correspondencia. Los «muchissimos [...] obras mas papeles» dados al duque pueden referirse al tratado de Soler, Llave de la modulación, que podía haber sido completado —al menos en su mayoría - para marzo de 1761 , pero que no tenía todavía apoyo financiero.

Además, se averigua que Soler tenía un hermano, músico en la Guardia Valona, la escolta personal del rey, y como se llamaba igual que su padre (Matheu, en catalán) era posiblemente un hermano mayor. Mateo Soler nació en Martorell, en la diócesis de Barcelona. Fue nombrado primer fagot en la Capilla Real en 1780 y murió en Madrid en 1799. ${ }^{17}$

El Duque de Medina Sidonia tocaba también el clavicordio: «la unica diversion que conservo de las que me entretubieron en mis primeros años.» ${ }^{18}$ Tenía un clavicordio «con toda la

16. ADMS, Leg. 2346, Soler al Duque de Medina Sidonia, 16 de marzo de 1761.

17. Véase SALDONI, Baltasar: Diccionario biográfico-bibliográfico de efemérides de músicos españoles (Barcelona, 1881), págs. 140-141; y García Marcellán, José: Catálogo del Archivo de Música del Palacio de Oriente (Madrid, s. a.), págs. 272 y 322 .

18. ADMS, Leg. 2350, Duque de Medina Sidonia a fr. Nicolás de Santa María, «Religioso Geronimo de mi Conb. ${ }^{\text {to }}$ de S. " Isidro del Campo Extra mura de Sevilla» [fundado para el hijo de Guzmán el Bueno]: «Acepto gustoso la oferta que V. R. me hace de algunas tocatas para el Clave, pues es esta la unica diversion que conservo de las que me entretubieron en mis primeros años, [...]»14 de septiembre de 1762 . 
extensión de teclado» - esto es, con 5 octavas - en su cuarto de la casa de Madrid en la Puerta de la Vega, adyacente al Palacio de Oriente. Su clavicordio tenía un extra D' y D\#' («el de/se faut ultimo del vajo, y el de/se faut sustenido»). ${ }^{19}$ Su esposa tenía un clavicordio más pequeño en su cuarto de la casa en Madrid. Ella tomó lecciones de clavicordio de Miguel Rabassa, tercer organista de la Capilla Real. El Duque tenía también clavicordios en los sitios reales de Aranjuez y San Ildefonso.

Soler no volvió a escribir al Duque hasta casi tres años después (en enero de 1764), cuando le agradeció su regalo de Navidad, consistente en una lata de tabaco de la Habana de 6 libras. Soler recitó versos en un poema de 92 líneas dirigido al duque:

«Quasi cinco horas â Solas

desbuché alegres Sonatas,

repitiendo las pedidas,

por Vocencia, vezes tantas. ${ }^{20}$

En diciembre del mismo año Soler escribió otro largo poema de 146 líneas para el duque enviando saludos navideños y pidiendo otro regalo de tabaco:

\author{
$\ll S^{r}$ Vaia en Octavas. \\ $1^{\underline{a}}$ \\ Duque aunque ocupado estoi \\ con las Pascuas en mil cosas, \\ por sér tiempo de jocosas \\ coplas, escrivo estas hoy: \\ ô en la erradura daré, \\ Solo decirte sabre, \\ Sepas ya, que tuo soi.
}

\title{
DEZIMA.
}

Antes, que el Sol rompa hermoso, antes, que nueva Luz Rompa,

19. ADMS, Leg. 2360, Miguel Rabassa a Santiago Sáez, 16 de abril de 1765: «Mui S.r mio. Con la orden ${ }^{\circ}$ Vmd. me participo en la q. ${ }^{\text {e }}$ S. E. me manda parte casa de D. ${ }^{n}$ Diego [Fernández] el q. ${ }^{\mathrm{e}}$ hace los clavicordios â ver uno que tiene ultmam. ${ }^{\text {te }}$ acabado, lo esecuté ayer tarde, y he encontrado un clave como $\mathrm{S}$. E. Io desea con toda la extension de teclado igual al que tiene el clavicordio de q. ${ }^{\text {e }}$ Su Ex." se sirve en su quarto, menos el de/se faut ultimo del vajo; y el de/se faut sustenido; no obstante que lo allá desafinado me he pareciado muy bien aunque las voces no son tan finas y delicadas como las del clave de S. Ex. ${ }^{a}$ sobrina [Marianna de Silva, Duquesa de Huéscar, madre de Cayetana] me ha dicho qe este, y el del Infante D. ${ }^{n}$ Gabriel son los mas excelentes que se han êcho de este corte; y haviendo pasado â ajuste me ha dicho $\mathrm{q}^{\mathrm{e}}$ no tiene orden de tratar de esto, y que resp. ${ }^{\text {to }}$ que su tio está en Aranjuez, puede D. ${ }^{n}$ Juan Anto. ${ }^{\circ}$ Escudero verse con el y tratar en materia de precio; Y con esta ocasion si Vmd. no incombeniente de hacer presente â nrô. Ami. ${ }^{\circ}$ D. ${ }^{n}$ Juan Anto. ${ }^{\circ}$ Escudero que de la mesada q. S. Ex. ${ }^{a}$ me tiene consignada de parte del difunto Pareja se me debenderse fin de Diz. ${ }^{\text {bre }}$ del año pasado de 1764 hasta el presente, las mesadas corr. ${ }^{\text {tes }}$ y mas veinte r. ${ }^{\text {s }}$ de la copia de una Sonata y Minuetes del Musico Prusiano, le he de merecer a Vmd. se lo advierta, y al mismo tiempo ruegue ofrezca mi respectos a los P.s de S. E. Vmd. mande a su verdadero y afecto Ami. ${ }^{\circ}$ hoy 16 ./. Miguel Rabasa»

20. ADMS, Leg. 2356, Soler al Duque de Medina Sidonia, 7 de enero de 1764. (Véase Addendum I). 
Emanuél Niño gracioso,

Le tengas Tabaco este año, porque en los nidos de antaño

(Segun llego â Colegir

de este polvo) he de decir,

que no hai Pajaros Ogaño.» ${ }^{21}$

El duque envió rapé. Soler escribió una carta muy breve de agradecimiento al duque un mes más tarde:

«S. ${ }^{\mathrm{r}}$ recivi el Polvo, que por aver estado en una granja de Casa, no ha correspondido $\mathrm{mi}$ agradecim $^{\text {to }}$ a la dicha fineza. Espero nos veremos presto aunque no se de fixo quando, tengo el tiempo mui corto, y no puedo ser mas largo, hasta la vista.» ${ }^{22}$

En marzo de 1765 Soler oyó las noticias del nombramiento del duque y su esposa para formar la corte de los Príncipes de Asturias, el futuro Carlos IV y María Luisa de Parma. Fue su excusa para una gozosa carta de felicitación «para manifestar a V. E. la alegría que ocupa a todo mi alma.»

«S. ${ }^{r}$ Si las Alas de mi amor, contáron de Plumages, que dividir pudieran al Aire, no fuera su fortaleza capáz de interrumpir mi acelerado buelo, para manifestar â V. E. la alegria, que ocupó â toda mi alma, la feliz nueva de los nuevos empleos, que han recaido en las Personas enlazadas por el Santo Sacramento, esso es V. E. con su Amante Esposa, en el nuevo servicio de mi Amo, y S. ${ }^{r}$ el Gran Principe, y Princesa de las Españas: Sea pues mil vezes para bien, y mil vezes sea en hora buena, la que suplico haga presente â su amada Sunamitis, como que deseo la gozen con felicidad interin se va ascendiendo en grado de maior corona.» ${ }^{23}$

La efusión de la carta de Soler hace sospechar que quizás él vio la posibilidad de jugar algún papel en la elección del duque como por ejemplo el de «maestro de música» de María Luisa, como Domenico Scarlatti lo había sido de María Bárbara de Braganza.

Pero el duque tenía otro trabajo para Soler, uno no tan grandilocuente como el de «maestro de música» de la futura reina. La carta del duque a Soler seis meses más tarde puso en movimiento una cadena de acontecimientos que pondrían a prueba a dos hombres y revelarían el verdadero carácter de Soler. Un borrador de la carta del secretario del duque muestra correcciones / subrayado / y sustituciones [+] del duque:

21. ADMS, Leg. 2360, Soler al Duque de Medina Sidonia, 19 de diciembre de 1764. (Véase Addendum II).

22. ADMS, Leg. 2360, Soler al Duque de Medina Sidonia, 27 de enero de 1765.

23. ADMS, Leg. 2360, Soler al Duque de Medina Sidonia, 13 de marzo de 1765. Igualmente gozosa era la carta de congratulación de Carlo Broschi («Farinelli») de Bologna al duque: «Dá questo reconosco piu atti, tutti degni del suo bel core verso de mé perché mi chiama partecipe de farli avvenimenti d'ella sua Rispettabil Casa, é mi prova ch'ella conosce quanto contento ne havrei á tal gioiosa notizia.» (ADMS, Leg. 2360, Carlo Broschi al Duque de Medina Sidonia, 2 de abril de 1765.) 
«R. ${ }^{\text {mo }}$ p. ${ }^{\mathrm{e}}$

Señor mio. Un Exc ${ }^{\text {te }}$ Chico /portador de esta se/ llamado Pedro de Santaman natural del Principado de Cathaluña, y que ha estudiado la Música en la Escuela de Monserrat vajo la direcc. ${ }^{\text {on }}$ de los Padres Cosme, y Phelipe Andreu.+[+ he visto executar maravillas en el

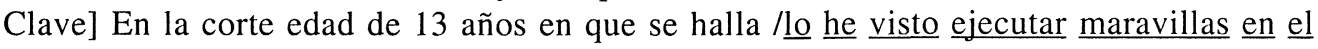
clabe/ aviendo una inclinacion mui grande a seguir la carrera de este estudio; por lo que y carecer sus Padres a medios con que cultivar tan buenas disposiciones he querido encargarme de costearle su manutencion y enseñanza len el dicho Arte/. Mediante lo qual sup. ${ }^{\text {co }}$ a V. R. se sirva decirme si abrá en ese R. Monasterio comodidad para su alojam. ${ }^{\text {to }}$ y que V. R. pueda tomar â su cargo el acavarle de /enseñar/ [+instruir] y perfeccionar en dha. Arte, avisandome tambien V. R. las prebenciones de Cama, vestido, $\&^{\mathrm{a}}$ y situado diario

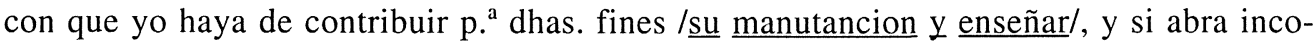
mo. ${ }^{\text {te }}$ en que /principiada esta/ le traiga yo â esta Corte algunas temporados a que se divierte en las prox. ${ }^{\text {mas }}$ fiestas R. ${ }^{\mathrm{s}}$ se con otros motivos que occuran.

Ma. ${ }^{d}$ y Julio 9 de $1765 »^{24}$

Soler contestó en dos días, tras haber hecho arreglos para que el joven Santamant se quedara en la casa del cura de San Lorenzo. Le recordaba al duque que «fuera de mi clavicordio, no hai en esta en donde tocár, ni ponér las manos.»

«S Recivi la apreciable de V. E. que dandome una singulár complacencia, en perficionár al muchacho, y serbir â V. E. Tocante â su habitación La tendrá, en el sitio en casa del S $\mathrm{I}^{\mathrm{r}}$ Cura+ [al margen: + se llama el cura del sitio de S. ${ }^{\mathrm{n}}$ Lorenzo, D. ${ }^{\mathrm{n}}$ Juan Garcia Maroto] quien para su manutencion de piso, comida, y Lavarle La Ropa pide 4 Reales diarios, dice le dará tambien catre para dormir, lo demás traterá el chico, quando venga.

Tocante â si podrá pasar â essa corte quando V. E. gustase, no hai inconveniente, aunque al principio de sus Estudios, no le será, me parece, mui util; con todo, yo como no he visto el chico, no puedo decir sobre esse punto cosa alguna de positivo. Me parece, que V. E. tendrá presente, que fuera de mi clavicordio, no hai en esta en donde tocar, ni ponér las manos; mas no sea esto motivo de que venga quanto antes, pues assi deseo remitirle â $\mathrm{V}$. E. para que logre de mis toscos pensamientos un vivo retrato.» ${ }^{25}$

Después de obtener permiso del prior de El Escorial para enseñar al joven, Soler escribió una carta de advertencia al duque el 14 de julio de 1765, en cubierta como una broma pero conteniendo una verdad más amplia:

«S $S^{\mathrm{r}}$. recivo la apreciable de V. E. Y aunque â la verdad no pide Resp ${ }^{\mathrm{ta}}$ Las ponderaciones de V. E. sobre el mucha ${ }^{\text {cho }}$. son de tanto Pabulo â mi deseo, que se me haze tarde ya la venida suia, que si el tiene tanto gusto en sér mi Discípulo, crea que con otro tanto me ofrezco â ser su Mํㅗ Y Ya se acordará V. E. que a mi me llamavan el Diablo vestido de fraile. pues tendré particulár gusto en $\mathrm{q}^{\mathrm{e}}$ esse Diablillo salga maiór Diablo.» ${ }^{26}$

24. ADMS, Leg. 2360, Duque de Medina Sidonia a Soler, 9 de julio de 1765.

25. ADMS, Leg. 2360, Soler al Duque de Medina Sidonia, 11 de julio de 1765 .

26. ADMS, Leg. 2360, Soler al Duque de Medina Sidonia, 14 de julio de 1765. 
Mientras el duque se hallaba con la corte en San Ildefonso, él puso en movimiento la fabricación de un clavicordio para las prácticas de Santamant. El agente del duque, Manuel Julián Gomalo del Río, escribió al secretario del duque en Madrid el 9 de agosto de 1765:

«Am. ${ }^{\circ}$ y S. ${ }^{\text {or }}$ Mi Amo me manda dezir â Vm. q. ${ }^{e}$ sobre la marcha haga hazér un cláve, como el q. ${ }^{\mathrm{e}}$ tiene S. E. aqui, ô p. ${ }^{\mathrm{r}}$ mejor dezir de Gesolrreut â Gesolrreut, de modo q. ${ }^{\mathrm{e}}$ se puedan tocár las sonátas de Escarlati, q. ${ }^{\mathrm{e}}$ bien sabe el q. ${ }^{\mathrm{e}}$ los haze, como debe sér, y Perico el cartero sabe donde vive, q. ${ }^{\mathrm{e}}$ créo há de sér en la Calle de las Huertas, ${ }^{\mathrm{s}}{ }^{\mathrm{s}}$ antes de venirse el chico al Escorial, le fué â llamár.$^{a}{ }^{a}{ }^{e}{ }^{e}$ compusiese una espineta, ô cláve pequéño, p. ${ }^{a}$ q. ${ }^{e}$ se la tragése al citádo Escorial. Luego, q. ${ }^{e}$ esté echo, se servirá Vm. avisármelo p. $^{a}$ vér, q. ${ }^{\mathrm{e}}$ dispóne $\mathrm{S}$. E. pues segun me há dicho quiere embiárselo al chico al yá nominádo Escorial, p. ${ }^{\mathrm{r}}$ no servirle la Espinéta.» ${ }^{27}$

Hacia mediados de agosto el joven Pedro Santamant ya había llegado a El Escorial y había tocado para Soler. El informe de Soler al duque carece de entusiasmo:

«S $S^{r}$ : Celebro la buena salud de V. E. La mia â $D^{s}$ q. e está siempre â la disposición de V. E. $S^{\mathrm{T}}$ el chico va algo mendado en La disposición, y portamento de la mano, aunque en tan corto tiempo: el talento es singulár, aunque hai mucho, que trabajár con el, y no sentiré otra cosa, que sino el que se me buelva â riciár, encargo, que lleva de mi $\mathrm{p}^{\text {te }}$. no hai mas lugár para ser mas lato.» ${ }^{28}$

Una semana después, sin embargo, la actitud de Soler hacia Santamant cambió totalmente. La razón se hace evidente en una nota escrita al margen de la carta de Soler:

«S $S^{\mathrm{r}}$ he visto el muchacho, y he adquirido nuevos deseos de hazerle hombre segun lo $q^{e}$ mi cortidad alcanze; Sobre el encargo $q^{e}$ V. E. me haze devo responder â V. E. que nunca ha sido mi Animo tratarlo como â muchacho, sino como â hombre de juicio, como si fuera mi mismo hermo ${ }^{\circ}$ y en fin el muchacho mismo será testigo de la complacencia, $q^{e}$ yo tengo en hallar en Genio como el suio, y tan parecido al mio, que quisiera todo el dia estarme estudiando, y con lo poco, $\mathrm{q}^{\mathrm{e}}$ le he tratado he conocido su aplicación y gana de sabér, que es quanto en breve puedo hazer presente â V. E.

[Al margen de la página 2:]

$\mathrm{E}^{\mathrm{mo}} \mathrm{S}^{\mathrm{r}}$ : acabo de recivir por expresion del afecto de V. E. asi Tabaco como pañuelos, y chocolate de lo $\mathrm{q}^{\mathrm{e}}$ doi las $\mathrm{g}^{\mathrm{s}} \mathrm{de} \mathrm{V}$. E., y cuidado por otra, $\mathrm{q}^{\mathrm{e}}$ por enseñar al chico con el Cariño, $\mathrm{q}^{\mathrm{e}}$ se merece, no necesita mas recomendación, ni mas paga que su mismo buen porte.» 29

27. ADMS, Leg. 2360, Manuel Gamalo del Río a Santiago Sáez, 9 de agosto de 1765. Tocante a «the mystery surrounding the high G» de los clavicordios españoles del siglo XVIII, véase GILbERT, Kenneth (ed.): Antonio Soler: 14 Sonatas from the Fitzvilliam Collection (London, 1987), pág. VI; y MARTíNEZ Cuesta, Juan, y KenYON DE PASCUAL, Beryl: «El Infante Don Gabriel (1752-1788), Gran Aficionado de Música», Revista de Musicología, XI (1988), pág. 770.

28. ADMS, Leg. 2360, Soler al Duque de Medina Sidonia, 16 de agosto de 1765.

29. ADMS, Leg. 2360, Soler al Duque de Medina Sidonia, 24 de agosto de 1765. 
Durante la visita de la corte a El Escorial en 1765, el duque escribió, el 3 de noviembre, al embajador veneciano, Geronymo Ascanio Justiniani: «Fray Antonio Soler hace cada día mejores sonatas y hace más mucha memoria de V. E.» ${ }^{30}$

El duque salió de El Escorial y regresó a Madrid antes de acabar noviembre. El 27 de noviembre de 1765 Soler le escribió una carta sorprendente, expresando su intención de tocar ante la Princesa de Asturias, María Luisa, y entregarle como regalo algunas de sus sonatas:

«S el tiempo no permite $q^{\mathrm{e}}$ yo cumpla como deseo en rendir mis respetos personalm. ${ }^{\text {te }}$ a las ordenes de V. E.

Oy he pasado al Cuarto de Madama Gonzalez, y aviendo dado el Recado por parte de su hijo Gonzalez, me fue respondido que respeto que la Princesa estava en cama, que me esperase para una ocasión en Madrid en donde me favorcerla para $\mathrm{q}^{\mathrm{e}}$ Tocarse delante Su Alteza: En fin le dixe â Gonzalez que tomase las sonatas y se las entregara â su madre, y $\mathrm{q}^{\mathrm{e}}$ se las presentara en mi nombre a la Princesa quando gustase, $\mathrm{Y}$ aun a esto me repondió, $\mathrm{q}^{\mathrm{e}} \mathrm{S} .^{u}$ Alt. ${ }^{a}$ no toman cosa alguna sin hazer particulár Regalo, a lo que respondí, que yo no queria Regalo alguno, ni menos avia soñado en ella, y que para que $S$. A. supiese mi buen afecto, me bastava el $\mathrm{q}^{\mathrm{e}}$ en qualquiera tiempo q. ${ }^{\mathrm{e}}$ gustase su madre se las presentase de mi p. ${ }^{\text {te }}$ y con esto le dexé las sonatas, en sus Manos, y me fui sin ver ni â Madama Gonzalez, ni a Mi $S^{\text {ra }}$ La Princesa mui contento.

CAP. 2. DE OTRA COSA.

S. ${ }^{r}$ el S. ${ }^{r}$ Cura, quien tiene en su cargo al chico de Santamán, me ha pedido suplicase â V. E. que respeto de que el año ha sido tan esteril (aunq e es verdad que se ajustó por $4 \mathrm{r}^{\mathrm{s}}$ diarios, y sino es del agrado de V. E. le mantendrá solo por cumplir la Palabra, que tiene interpuesta) y los abastos tan caros:

Supp ${ }^{\underline{c a}} \hat{a}$ V. E. se digne aumentarle $2^{\underline{s}} r^{\mathrm{s}}$. mas, que serán 6 , y q $q^{\mathrm{e}}$ puede V. E. descansár en $\mathrm{q}^{\mathrm{e}}$ se asistirá â dicho Pedro, ô con 4 ô con 6 siempre con la maior decencia, y cuidado, que si fuese hijo propio.

CAP. 3. DE OTRA COSA.

$S .^{r}$ el $p^{e}$ Pinto de $S^{n}$ Juan de Dios me ha dicho esta mañana, que partia para Madrid sobre la marcha: y que llevava muchos encargos de Sus Altezas Reales, por cuio motivo, no podia complazér â V. E. en el encargo de un Plan, que le avia pedido.

Yo me rindo S. ${ }^{\mathrm{r}}$ con todo mi afecto a los ordenes de V. E. y quedo rog ${ }^{\text {do }}$ á Dios le

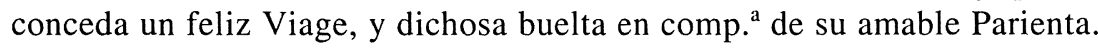

[Posdata:]

Lunes pasado se, que el Rey el $S^{\mathrm{r}}$ Patriarca, y $\mathrm{D}^{\mathrm{n}}$ Americo Pini tuvieron una larga sessión sobre mi Persona, y me levantaron hasta los cuernos de la $\gg{ }^{31}$

30. ADMS, Leg. 2360, Duque de Medina Sidonia a Gerónimo Ascanio Justiniani, 3 de noviembre de 1765. Tocante al Embajador de la Serenísima República de Venecia, véase la Gaceta de Madrid, 20 de septiembre de 1757 (audiencia pública de S. M.); Clarke, pág. 129 (entrada en Madrid, 1760); y KIRKPATRICK, pág. 400 («Libro de Sonatas de Clave para el ex. ${ }^{\mathrm{mo}} \mathrm{s} .{ }^{\mathrm{r}}$ Eñbaxador de Benecia de $\mathrm{D}^{\mathrm{n}}$ Domingo Scarlati»).

31. ADMS, Leg. 2360, Soler al Duque de Medina Sidonia, 27 de noviembre de 1765. Antonio Baciero publicó una «Sonata por la Princesa de Asturias» de Soler en Madrid, 1979, Biblioteca de los Duques de Villahermosa, en Pedrola. Las referencias a «un Plan» y a «un feliz Viage» pueden ser a la jornada en Italia de la Infanta María Luigie para su boda con el Infante D. Filippo, Duque de Parma, acompañada por la Duquesa de Medina Sidonia y tanto cuanto la frontera de Francia para el Duque de Medina Sidonia. Véase Ms. R23518 (Fondo Barbieri), Biblioteca Nacional, Madrid, para las fiestas de la boda en Italia a la que asistió Farinelli. 
Aún más sorprendente que el intento de Soler de tocar ante la princesa era la posdata de la carta: ¡el papel había sido arrancado en este lugar! ¿Cuál era el propósito de estas sobre-alabanzas de Soler? ¿Iba a ser tenido en cuenta para un nombramiento real?

Menos de dos semanas después, el 8 de diciembre de 1765, Soler escribió al duque, agradeciéndole los 20 doblones que había recibido del agente del duque, «los que me ha satisfecho con su servidumbre al Papél impreso q ${ }^{\mathrm{e}}$ dí al Publico.» La refutación de Soler de 78 páginas, titulada Satisfacción a los reparos precisos hecho por D. Antonio Roel del Rio, en contra de un ataque a su Llave, fue publicada en Madrid en 1765. Después de comunicar al duque que «hasta aora vamos bien» con él y «Perico» Santamant, Soler pidió al duque otro regalo, un reloj de repetición:

«Para V. E. Solo.

S. ${ }^{r}$ me alegraré, $q^{e} V$. E. se mantenga sin la menór novedad en la salud, Perico, y yo â D. ${ }^{s}$ g. ${ }^{s}$ gozamos de este beneficio para servir â V. E.

Doi mil g. ${ }^{\mathrm{s}}$ â V. E. por los 20 Doblones, q. ${ }^{\mathrm{e}}$ recivi por mano del S. ${ }^{\mathrm{r}} \mathrm{D}^{\mathrm{n}}$ Manuél [Gamalo del Rio], Los $\mathrm{q}^{\mathrm{e}}$ me han satisfecho con su servidumbre al Papél impreso $\mathrm{q}^{\mathrm{e}}$ dí al Publico, y por fin este año he podido salir â $\mathrm{D}^{\underline{s}} \mathrm{G}^{\mathrm{s}}$ de los atrazos, $\mathrm{q}^{\mathrm{e}}$ avia llevado a cuestas desde $\mathrm{q}^{\mathrm{e}}$ entré mi herm. ${ }^{\mathrm{a}}$ Religiosa.

V. E.

Tocante â Perico hasta aora vamos bien en un todo, $\mathrm{q}^{\mathrm{e}}$ es lo unico puedo participár â

S. ${ }^{r}$ si V. E. no ha de llevár â mál, el q ${ }^{\mathrm{e}}$ me tome la licencia para suplicarle un favór $\mathrm{q}^{\mathrm{e}}$ es lo unico que me haze falta pues he dado en vigilár, y vestirme mas vezes a la $1 .^{\mathrm{a}}$ de la mañana, otras á la dos etc. es Señor una muestra pequeña de Repetición con tal q $\mathrm{q}^{\mathrm{e}}$ no sea de oro, ni plata. Si es posible, que con solo ser de similár me basta, ande ella bien, q el oro, ni plata no me acomoda.

Esta venido el dueño del Relox $q^{\mathrm{e}}$ tenia $\mathrm{q}^{\mathrm{e}}$ daba horas, y se le ha buelto ha llevár, con esto de noche ni se $\mathrm{q}^{\mathrm{e}}$ hora es, ni menos se oie el Relox de la Torre cerradas las puertas de la celda en $\mathrm{q}^{\mathrm{e}}$ me he mudado, $\mathrm{q}^{\mathrm{e}}$ mira al medio dia, y es mui capaz, y hermosa.» ${ }^{32}$

El duque accedió a comprar el reloj a Soler, ${ }^{33}$ y el 9 de enero de 1766 Soler escribió al duque una breve carta con un regalo de «4 Caxas de Turrón» fabricado en el monasterio, con un recordatorio subrayado del reloj de repetición:

«S: La priesa de la partida del Proveedór de Casa no me da lugár $\mathrm{p}^{\mathrm{ra}}$ mas, $\mathrm{q}^{\mathrm{e}}$ hazér presente â V. E. La fineza con $\mathrm{q}^{\mathrm{e}}$ regala â V. E. + [al margen: + son 4 Cajas de Turrón fabricada en esta] mi Periquito de Aguinaldo, $\mathrm{q}^{\mathrm{e}}$ le han regalado los $\mathrm{R} \mathrm{P}^{\mathrm{s}}$ recivalo $\mathrm{V}$. E. con gusto, y perdone La Cortedád: no quiero repetir por no molestár a V. E.» ${ }^{34}$

32. ADMS, Leg. 2360, Soler al Duque de Medina Sidonia, 8 de diciembre de 1765. En la Satisfacción (pág. 63), Soler cita cuatro libros de clavicordio que en 1765 tenía ya compuestos.

33. ADMS, Leg. 2360, Duque de Medina Sidonia a Soler, 10 de diciembre de 1765.

34. ADMS, Leg. 2364, Soler al Duque de Medina Sidonia, 9 de enero de 1766. 
El proximo día el duque respondió con otra breve carta a Soler agradeciendo a «Periquito de lo que le há tocado por su Aguinaldo, a q. ${ }^{\mathrm{n}}$ dará V. $\mathrm{R}^{\mathrm{ma}}$ de mi parte un abrazo, diciendole le estimo mucho su memoria...» ${ }^{35}$

Dos semanas después Soler todavía no había recibido el reloj. Escribió de nuevo, regañando al duque con sarcasmo por no haberlo enviado:

«S $\mathrm{S}^{\mathrm{r}}$ : con el motivo de dar â V. E. alguna razón, y noticia de Perico Santamán, y su estado, tomé La Pluma gustoso, para explicar â V. E. mi deseo, el que creo servirá de acuerdo, pues la memoria me parece faltó: Sea como se sigue:

Ex ${ }^{\frac{\mathrm{mo}}{\mathrm{O}}} \mathrm{S} .^{\mathrm{r}}$ me alegraré $\mathrm{q}^{\mathrm{e}} \mathrm{V}$. E. no tenga tan frias mañanas como yo, pues teniendo el Quarto elado, la hora sin son los mas de los dias me levanto sin ton, ni son, esta Repetición de actos, que no dá (V. E.) bien se dexa discurrir, quan penosas jornadas me acarrea: Siento el acordarlo, pues tal vez no será olvido, si importunidad mia, que seria mejor callárlo.

Me pareze se dispone la Pluma para el verso, vaia pues una

\section{$\underline{\text { Dezima }}$}

Si es que es un Relox mi Pluma, que le pesa el Repetir, porque yo no he de decir, que â todas horas me bruma? tome tinta, y deje espuma venga ya el Inglés tál, quál, sea Plata, ô bien metál, $\mathrm{Y}$ en buelto vaia al Retiro, Que con esso ya no aspiro, Duque, a Repetir mi Mál.

[Sabiendo como obtener una respuesta del duque, Soler encontró defectos en su joven estudiante:]

«Perico S. ${ }^{\mathrm{r}}$ ha sentido mucho el frio, como nosotros tambien, pues nunca, dicen los Ansianos, se diá conocido maiór, adelanta, y pule mui bien el manejo, pero en la composición, y fondo está en mi dictamen, y del mismo Perico, mui atrasado; con todo, espero en $D^{s}$ que saldremos victoriosos de ntra campaña: está el Pobrecito cada dia mas pasmado, de ver, $\mathrm{q}^{\mathrm{e}}$ en mi corredád advierte: y yo procuro en todo animarle.» ${ }^{36}$

Soler no desconocía que el nombre de pila del duque era Pedro y que sus amigos nobles le llamaban «Perico.»El duque respondió a la carta de Soler dos días después con la noticia de que el reloj había sido comprado y sería enviado:

35. ADMS, Leg. 2364, Duque de Medina Sidonia a Soler, 10 de enero de 1766.

36. ADMS, Leg. 2364, Soler al Duque de Medina Sidonia, 22 de enero de 1766. 
«Señor mio. R. ${ }^{\text {vo }}$ la de V. R. de 22 del corr. ${ }^{\text {te }}$ estimando lo mucho las noticias que me dá de la aplicacion del chico, y no dudo que con ella, y sobre todo con la buena enseñanza que logra en V. R. acabará de perfecionarse en la intelig. ${ }^{a}$ de la composición.

El Reloj hace dias que está comprado y que tengo dada orden de que se remita a V. R. y sino le ha llegado consistirá en no haverse presentado conducto seguro por donde encaminarle y así podrá decirme V. R. a que persona de esta Corte se le deberá entregar para que se dirija a V. R. a quien repito mi buena voluntad de servirle... ${ }^{37}$

Dos días más tarde, el 26 de enero de 1766, Soler escribió de nuevo, agradeciendo al duque el reloj que aún no había llegado, vituperando a Santamant con débiles alabanzas y presumiendo se su propia habilidad como maestro. También cita a su propio maestro (según su Llave de la modulacion), José de Nebra (1702-1768), primer organista y vicemaestro a la Real Capilla $\mathrm{y}$ «Maestro de clavicordio del $\mathrm{Sr}^{\mathrm{mo}}$. $\mathrm{S}^{\mathrm{r}}$. Infante $\mathrm{D}^{\mathrm{n}}$. Gabriel.»

«S $\mathrm{r}$ : Reciví La apreciable, y estimadissima carta de V. E. alegrandome sobre todo de la Salud, $q^{\mathrm{e}}$ el Benigno S.r se digna concedér â V. E.

Sobre el assumpto de Perico, S. ${ }^{r}$ me alegrára ser Dios por un instante, que en el acta de darte toda la sabiduria posible, pero esso no puede sér, y el es un niño aplicado, y de pocas fuerzas, es verdad tiene alguna culpa en averse olvidado del fondo, $\mathrm{q}^{\mathrm{e}}$ le enseñaron, pero es precisa la paciencia la $\mathrm{q}^{\mathrm{e}}$ tengo, y tendré gustoso, assi por su credito, como por el mio: en el tocár, y asiento del compás está ya mui otro, pero para trabajár de suio necesita estár bien en la Composición esta pide tiempo, y creeré, sea todo completo por el tiempo, $\mathrm{q}^{\mathrm{e}}$ tengo señalado. No hai que dar priesa, acaso no se biente el cavallo en la carrera; y como dice mi Insigne Nebra: primero es el cappellan, que la cappellania: yo deseo, quanto antes entregár â Perico, echo hombre: V. E. desea tenér â Perico con las mismas circunstancias, pues Amigo tengamos paciencia los dos, si no queremos Lográr y ver nuestro gozo en un Pozo.

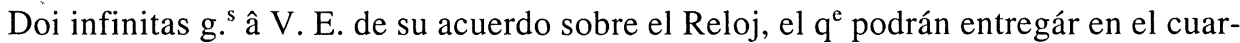
to del nuevo Lord o â qualquiera de los dos R.P. ${ }^{s}$ Administradores, $\mathrm{q}^{\mathrm{e}}$ el maior se llama $\mathrm{P}^{\mathrm{e}}$ fr. Diego Alvárez, y el Seg. ${ }^{\text {do }} \mathrm{P}^{\mathrm{e}}$ fr. Pedro Torres, que ellos me le remitirán seguro en la primera ocasión para casa.

[Al margen:] haora acaba de llegár Perico, a quien he Leido la de V. E. estima las amantes espresiones de V. E. las $\mathrm{q}^{\mathrm{e}}$ devuelve con encarecido affecto, y dice en Catalán, Les parecerá, que no hai mas que soplár, para trabajár el vidrio.. ${ }^{38}$

Unos días más tarde Soler escribió al duque diciendo que había recibido el reloj pero lamentándose que era «un oro, como cosa de un Grande.» Lo guardaría en el depósito del monasterio hasta que algún otro, menos adornado, fuera encontrado. Acabó la carta con una ligera alabanza a Santamant, ahora llamado «Periquito.» El verdadero carácter de Soler se nos revela algo más.

37. ADMS, Leg. 2364, Duque de Medina Sidonia a Soler, 24 de enero de 1766.

38. ADMS, Leg. 2364, Soler al Duque de Medina Sidonia, 26 de enero de 1766. 
«S. ${ }^{r}$ Los acreditados favores con que V. E. me honrra, pudieran ya azer sencillas mis particulares demandas: Recivi La Repetición, y por ser ella un Oro como cosa de un Grande, a fe mia S. ${ }^{r}$ que la estimo mas no me sirve; pues no se toleran en nuestra Religión semejantes alajus. La muestra S.r tengo puesta en el Deposito, esperando, que V. E. me responda â una de estas dos cosas; ô bien enviarme otra de Plata, que de esta me podré servir, y devolveré â V. E. la de Oro, $\mathrm{q}^{\mathrm{e}}$ no puedo usár; ô darme el Permiso, para $\mathrm{q}^{\mathrm{e}}$ de la de Oro se agencie otra de Plata, quedando V. E. aun Dueño de lo $q^{e}$ valga más: Yo estimo, agradezco, y doi g. s â V. E. por su magnanimo pecho, pero bien sabe V. E. q en Las dos mias, $\mathrm{q}^{\mathrm{e}}$ no fuese de Oro.

Periquito â D. ${ }^{\text {s g. }}$ goza salud. Se aplica mucho, y ha templazado los atrasos, y segun esta Señal espero, que se le podré dexár â V. E. en el Sig. ${ }^{\text {te }}$ año â temporadas; $q^{e}$ es quanto de nuevo hallo desde la passada.» ${ }^{39}$

El duque contestó al día siguiente diciendo que Soler pudiera «disponer como dueño de la muestra de Reloj que le ha remitido cambiandola, ô vendrendola como le pareciere hasta que la logre V. R. de las circumstancias que desea.» El duque se gozó en el aforismo de Perico:

«Señor mio. Doi resp. ${ }^{\text {ta }}$ a la de V. R. de 30 del que acaba diz ${ }^{\text {do }}$ puede desde luego disponer como dueño de la muestra de Reloj que le he remitido cambiandola, ô vendrendola como le pareciere haste que la logre V. R. de las circunstancias que desea, pues por acá no se ha hallado cosa mas adequada que enbiar a V. R. aqui en ultimo las noticias que me dá del chico, y me reito á su idio. ${ }^{\mathrm{ma}_{\gg}}{ }^{40}$

No hay correspondencia entre el duque y Soler durante los cuatro meses siguientes. El 13 de marzo de 1766 Soler firmó su segunda refutación a los ataques a su tratado, titulado Carta escrita a un amigo. Quizás este panfleto de 13 páginas fue financiado con el dinero ganado al cambiar el reloj de oro que el duque le envió. Soler envió al duque una copia en julio con una breve carta:

«S. ${ }^{\mathrm{r}}$ Por quanto concibo se alegrar â V. E. y aun divertirá alguna cosa, remito este impresso adjunto, $p^{\text {ra }} q$ V. E. le lea, y se sirva con el, espero le recivira con gusto, pues aunq $^{\mathrm{e}}$ cosa corta le embia el dilatado, y obblig. ${ }^{\circ}$ affecto de un Apassionado de V. E.» ${ }^{41}$

El 26 de marzo de 1766 Soler firmó la extensa necrología de fr. Pedro Serra, condiscípulo suyo en Montserrat y tañedor de oboe, flauta y fagot en San Lorenzo, para las Memorias sepulcrales.

El 3 de junio Soler escribió un informe acerca del progreso de Santamant para el duque, que pidió a «Don Luis [Marescalchi]» que visitase «de parte de V. E. para informarse igualmen-

39. ADMS, Leg. 2364, Soler al Duque de Medina Sidonia, 30 de enero de 1766.

40. ADMS, Leg. 2364, Duque de Medina Sidonia a Soler, 31 de enero de 1766.

41. ADMS, Leg. 2364, Soler al Duque de Medina Sidonia, 10 de julio de 1766; breve carta con una copia de Carta escrita a un amigo. (Véase nota 15 relativa a los tratados de música). 
te del estado y porte de Perico.» Quizás Marescalchi, el nuevo director de los teatros de los sitios reales estaba realmente ahí para comprobar si Santamant estaba listo para tocar en la orquesta de la ópera. Pero Soler no estaba dispuesto a perder a Perico:

«S. ${ }^{r}$ por tenér ocasión de portadór propio, y conocer que V. E. estará deseoso de mis toscos caractéres, escrivo gustoso para complazér â V. E. y rendir mi amante corazón, y fina voluntad â las Ordenes de V. E.

Perico â D. ${ }^{s}$ g. ${ }^{s}$ gasta salud, y no es posible, que io pueda explicár â V. E. quan poco fundamentado estaba, ni el es capáz de decir como he hecho vencér muchas cosas, que le parecian imposibles; en fin S. ${ }^{r}$ con el mas solido fundam ${ }^{\text {to }}$ que tiene ntra facultád, ha passado todos los mas asperos, y dificiles caminos de la composición, y espero que en esse mes, empieze â travajár algun Salmo: y en el sig. ${ }^{\text {te }}$ empieze â travajár de Clavicordio. Si V. E. quiere Lográr al muchacho, y que mi travajo sea tanto, es preciso que por haora no dexe la Escuela, pues están las cosas mui tiernas, y con facilidád las puedo olvidár, que desde el mes de $8^{\text {bre }}$ podrá dár ya sus voladillas, y lo contemplo necesario, pero ahora nó: V. E. perdonará mi llaneza, pues mas ganas tengo yo de azerle hombre, que V. E. de lo que sea: un día, que pierda ahora equivale á un Mes. Y el Mes al Año.

El S. ${ }^{r}$ Cura con quien está, me dixo, que avia embiado dias passados un Recivo el Maiordomo de V. E. $\mathrm{D}^{\mathrm{n}}$ Ant. ${ }^{\circ}$ no me acuerdo del Apellido, $\mathrm{p}^{\text {ra }}$ cobrár el medio Año, y parece se le volvió â Remitir diciendole que el no tenia orden alguna, y q escriviesse â la $S$. Duquesa que con su Orden al instante se satisfacia: el bueno del Cura no savia que hazerse, y yo le dixe que yo escribirla â V. E. y el ofrecí dinero, me respondió, que no lo necesitaba por ahora, sinó que avia enviado el Recivo $\mathrm{p}^{\text {ra }} \mathrm{q}^{\mathrm{e}}$ fuessen en las cuentas acordes. Espero, que V. E. me dirá, que se ha de hazér sobre esse punto, que io deseo cumplir las ordenes de V. E.

D. ${ }^{\mathrm{n}}$ Luis vino hazerme una visíta de $\mathrm{p} .^{\text {te }}$ de V. E. para informarse igualm..$^{\text {te }}$ del estado, y porte de Perico, g â a Dios no me puede quejár, antes estoi mui contento con el. que es quanto se me ofrece.

[Posdata:]

Reciva V. E. y la Ex ${ }^{\frac{\text { ma }}{\text { a }}} S^{\text {ra }}$ Parienta mil expresiónes de Perico, que por no danos lugar la partida del Portadór, no ha escrito; le haré escrivir la primera ocasión, que tengamos; igualm. ${ }^{\text {te }}$ rindo mis Respetos â V. E. y la Parienta.» ${ }^{42}$

Perico Santamant escribió una carta al duque unos pocos días más tarde, el 8 de junio de 1766, con la ayuda de Soler. Aun así, algo del encanto del muchacho de 14 años se filtra:

$\ll S^{\mathrm{r}}$ : Mi afecto y reconocimiento cerca la Persona estimadissima de V. Ex. ${ }^{a}$ nunca se aminorado un tilde Por loque puede V. Ex. ${ }^{a}$ hazerse el cargo no aver escrito tanto tiempo ha. La aplicacion al estudio no se me minora, motivo que mi P. Mtro. no pierde el animo de hazerme hombre. Cada dia conozco mas lo mucho devo a V. Ex. ${ }^{a}$ en averme puesto en

42. ADMS, Leg. 2364, Soler al Duque de Medina Sidonia, 3 de junio de 1766. El discípulo de padre Martini de Bologna, Luigi Marescalchi (1745-1805), compuso su ópera bufa, «Il proseguimento del chiarlone», en Madrid en el invierno de 1765. Se representó la misma en San Ildefonso el verano de 1767. Véase New Grove Dictionary of Opera, III, pág. 208 y Martín Moreno, pág. 368. 
tal Escuela, pues sí; loque no pensava avia $q^{e}$ estudiar; soi haziendolo lo que crei me era imposible aprender; pensaba que, que sabia algo y cada dia seo, que aunq ${ }^{\mathrm{e}}$ ignoro menos, no sabia nada. Sobre todo hago a V. Ex ${ }^{a}$ que me aturdo Como me enseña pues acuerdome allo, sin sabér como ha sido que ya me lo metio en la cabeza. Dos mil g. ${ }^{\mathrm{s}}$ a Dios ya V. Ex. ${ }^{\mathrm{a}}$ que solamente, puedo Corresponderle siendole todos los dias de mi vida agradecida y encomendarle a D. ${ }^{\mathrm{s}} \sin$ obligarme como lo hago; y tambien â mi $\mathrm{S}^{\text {ra }}$ la Duquesa a cuyos pies igualmente rindo mis afectos.

[Posdata:]

Ex ${ }^{m o} S^{r}$ al acabar de escrivir esta repare mis torados renglones que aunque puse muchissimo cuidado para yr deve horo lo logre. V. Ex ${ }^{\underline{a}}$ me perdone y para otra procurare enmender este yrro. Pedro de Santamant.» ${ }^{43}$

Tres días mas tarde el duque - de 42 años y que no tenía hijos- esbozó una respuesta a la carta de Perico, dando consejos paternales al muchacho:

«R. ${ }^{\text {vo }}$ tu Carta de 8 . del corr. ${ }^{\text {te }}$ Celebrame mucho ver por ella que sobre la partida de habil tengas la de agradecido + [al margen: + prenda que yo estimo mucho] y espero que continuando en estas disposiciones, ni tu faltarás â aprobecharte, de la excelente enseñanza que logras, ni yo continuarte mi amor y protecc. ${ }^{\text {on }} \mathrm{h} .{ }^{\text {ta }}$ ponerte en paraje de que puedas ser hombre y atender á sus padres y hermanos en quanto alcances tus facultades.

Aranjuez Junio 11 de $1766 .{ }^{44}$

Durante casi 10 meses, Soler no escribió al duque. El 21 de octubre de 1766, el abate de San Lorenzo escribió al duque: «la celda de fray Antonio [Soler], y principalm. ${ }^{\text {te }}$ el servicio del Principe, q. ${ }^{\mathrm{e}}$ se halla solo en el dia, merecer ser preferidos...» ${ }^{45}$ En su carta al padre Martini de Bologna de 30 de noviembre de 1766, Soler se quejó: «si p. l'ocupazione avuta nella dimora della corte in questo Real Monasterio, essendo stato occupatissimo p. le Persone Reali, si ancora p. le funzioni solite a farsi nelle venture Sante Feste, nella composizione di cio che chiamiamo Villancicos nel ñro coro...». ${ }^{46}$

El 25 de marzo de 1767, Soler envió al duque una carta extrañamente sumisa y ambigua. Parece ser que Perico había sido sacado de la «escuela» de Soler y había hecho una de sus «voladillas» y se había estrellado —esto es, había recibido malas críticas.

«S: se me hazer tan Largas las Carnestolendas de este año, que aunque La Cuaresma entró en el Escorial, pienso que en la corte, durarán por todo el curso de las fiestas movibles. el dar principio â un edificio, y no conducirlo, es segun Christo, motivo de risa â los hombres. el Zelo de aver sido poco tiempo Maestro de Perico, me mueve â modulár estas clausulas. V. E. es Amo del, y Dueño de todos mis afectos, por tanto, puede mandarme en la forma que gustare, advirtiendo, que qualquiera que diga â V. E. que Perico se puede

43. ADMS, Leg. 2364, Pedro Santamant all Duque de Medina Sidonia, 8 de junio de 1766.

44. ADMS, Leg. 2364, Duque de Medina Sidonia a Pedro Santamant, 11 de junio de 1766.

45. ADMS, Leg. 2364, Abate D." Manuel R'omero al Duque de Medina Sidonia, 21 de octubre de 1766.

46. Kastner, Carta III, pág. 238. 
vandeár ya por si, aun por los mas conocidos passos de la facultad musica, en linea de M. ${ }^{\circ}$, crea V. E. a la palabra de Sacerdote, que interpongo, que engañan â V. E. y venden â Perico; y con esto ruego al todo Poderoso dilate la vida de V. E. los mas de mi deseo \&c.» ${ }^{47}$

Quiénes son los que «engañan» al duque y «venden â Perico» no está claro. Que Perico había sido sacado del tutelaje de Soler está en la réplica del duque dos días más tarde:

«Señor mio. Doy Respuesta a la de V. R. ${ }^{\text {ma }}$ de 25 del Corr. ${ }^{\text {le }}$ Estimandole mucho el celo con que mira por los adelantam. ${ }^{\text {tas }}$ del chico, y dispondre que quanto antes se buelsa á recivir las utiles y sabrás Lecciones de V. R. ${ }^{\mathrm{ma}{ }^{48}}$

El 4 de abril, Perico habla vuelto con Soler. Soler escribió sólo dos frases al duque:

«Señor: Perico llego en esta con perfecta Salud â D. ${ }^{s}$ g. ${ }^{\text {de. }}$ La mia queda â la justa disposicion de V. E.» ${ }^{49}$

Pasaron casi dos meses antes de que Soler escribiera de nuevo acerca del progreso de Perico:

«S. ${ }^{r}$ Por no averse ofrecido cosa particular, no he molestado a V. E. con cartas, esta solo sirve $\mathrm{p}^{\text {ra }}$ que V. E. sepa, que a D. ${ }^{\mathrm{s}}$ g. ${ }^{\mathrm{s}}$ hai salud, y se aprovecha el tiempo: Perico va ya haziendo sonatitas mui buenas, pienso que p. ${ }^{\text {ra }}$ el Corpus se pondrá cantár un Salmo suo, $\mathrm{y}$ tal véz sin ayuda de recivos; es quanto â la presente se me ofrece.» ${ }^{50}$

El duque respondió desde Madrid, el 26 de mayo:

«Señor mio. Estimo mucho las noticias que V. R. se sirve darme en esta de ayer de su buena salud y la de Perico, y de la aplicacion con que este se ba aprobechando de la sabia instrucc. ${ }^{\text {on }}$ de V. R. y espero que mediante ella podré lograr en brebe el questo de q. ${ }^{e}$ me divierta algunos ratos con habilidad. ${ }^{51}$

En agosto, Perico estaba con la duquesa en San Ildefonso durante la visita anual de la corte a La Granja. El duque estaba enfermo y permanecía en Madrid. Perico escribió al duque, muy excitado por la compañía italiana de ópera contratada en la corte para actuar en los teatros nuevos de los sitios reales:

«S. ${ }^{\mathrm{r}}$ me alegrare $\mathrm{q}^{\mathrm{e}}$ estas Cortas líneas encuentren a V. Ex ${ }^{\mathrm{a}}$ con la Perfecta Salud $\mathrm{q}^{\mathrm{e}}$ mi deseo quiere S. ${ }^{r}$ Estoy de en dia en dia esperando a V. Ex..$^{a}$ pasa V. Ex.. ${ }^{a}$ tenga una bue-

47. ADMS, Leg. 2368, Soler al Duque de Medina Sidonia, 25 de marzo de 1767.

48. ADMS, Leg. 2368, Duque de Medina Sidonia a Soler, 27 de marzo de 1767.

49. ADMS, Leg. 2368, Soler al Duque de Medina Sidonia, 4 de abril de 1767.

50. ADMS, Leg. 2368, Soler al Duque de Medina Sidonia, 25 de mayo de 1767

51. ADMS, Leg. 2368, Duque de Medina Sidonia a Soler, 26 de mayo de 1767. 
nos ratos y espero $\mathrm{q}^{\mathrm{e}} \mathrm{V}$. Ex $\mathrm{x}^{\mathrm{a}}$ ad estas gustoso la opera buena los bayles excelentes. La Veroni [cantante] La siempre q me se pregunta por V. Ex $x^{\mathrm{a}}$ y q espera tener La onrrade ver a V. Ex ${ }^{\mathrm{a}}$, cada dia canta con mas gracia y me a dicho q lo yo por quasualida [?] escribia alguna vez y dice a mil expreziones fiorini [autor de libreto y cantante en la ópera] esta un poco yndispuesto y me pregunta mucho por V. Ex ${ }^{\underline{a}}$ Pepito [joven clavecinista de la casa de los Duques de Medina Sidonia] va segiendo con Porreti [violoncelista] grandemente. Vea V. Ex ${ }^{\underline{a}}$ Si me manda alguna cosa siempre deseoso de dar gusto a V. Ex ${ }^{\underline{a}} q$ es mi Maiyor obligacion.» $^{52}$

Perico fue invitado a tocar en la orquesta de la ópera, pero Domingo Porretti, violoncelista en la orquesta y compositor cuyas obras Soler había citado en su propia defensa en su Carta, aconsejó a la duquesa que no dejase a Perico tocar solo o ante nadie, hasta que él lo dijese, y le aconsejó a sí mismo que no lo alabase demasiado porque «es la manera de echar.» Porretti dio clases diarias a Perico. ${ }^{53}$

Con la retirada otoñal de la corte a El Escorial, Perico regresó a sus estudios con el padre Soler. El duque continuaba enfermo con problemas dentales en Madrid. Perico le escribió desde San Lorenzo el 18 de noviembre de 1767:

«Señor Me alegraré q estas quatro líneas encuentren a V. Ex. ${ }^{a}$ con la perfecta Salud la $\mathrm{q}^{\mathrm{e}}$ mi afecto desea aqui enbio a V. Ex. ${ }^{\mathrm{a}}$ esos minuetitos Para $\mathrm{q}^{\mathrm{e}} \mathrm{V}$. Ex. ${ }^{\mathrm{a}}$ se divierta y Por si acaso V. Ex. ${ }^{a}$ los quiere regalas a mi S. ${ }^{\text {ra }}$ la Duquesa de huescar [sobrina del duque] aunq $^{\mathrm{e}}$ veo $\mathrm{q}^{\mathrm{e}}$ no es cosa digna de regalar. Espero enbiar a V. Ex. ${ }^{a}$ un Conciertito de Clave.

Aunq ${ }^{\mathrm{e}}$ es berdad $\mathrm{q}^{\mathrm{e}}$ desde $\mathrm{q}^{\mathrm{e}} \mathrm{V}$. Ex. ${ }^{\mathrm{a}}$ se fue estado bastante malo de las muelas $\mathrm{q}^{\mathrm{e}}$ me quitaban las ganas de todo. $\mathrm{Y}$ al $\mathrm{P}$. fr. Antonio [Soler] le e visto oy me dijo $\mathrm{q}^{\mathrm{e}}$ creia $\mathrm{q}^{\mathrm{e}}$ yo me avia ydo con V. Ex. ${ }^{a}$ Pero con todo le estudo mis licciones y yo avia trabajado.» ${ }^{54}$

En una carta al duque una semana más tarde Soler se quejó que «Perico se vá por orden de V. E.»:

«S. ${ }^{r}$ Celebraré, que la salud de V. E. se mantenga sin la menor novedad, como tambien La de mi $S^{\text {ra }}$ La Duquesa. La mia ofrezco â la disposicion de V. E. en todas ocasiones.

$S^{\mathbf{r}}$ doi â V. E. mil gracias por el socorro que se ha dignado darme sin merito mio alguno, solo procurare encomendár â Dios vivam. ${ }^{\text {te }}$ La importante salud de V. E. Perico se vá por orden de V. E. estimaré, que buelva prompto para emplearme de todas veras en su aprovechamiento, y se le bolveré â V. E. por la Primavera siguiente de todo punto impuesto en todo suerte de composición, mediante su cuidado espero, V. E. me dará este fabór por honrrar â mi, faborecer â el, y gloria, y gusto de V. E. cuia vida conserve el Todo Poderoso.» ${ }^{55}$

52. ADMS, Leg. 2368, Pedro Santamant al Duque de Medina Sidonia, 4 de agosto de 1767. Véase Cotarelo y MORI, Emilio: Origen y establecimiento de la ópera hasta finales del siglo XVIII (Madrid, 1917), págs. 197-198, y de BRITO, Manuel Carlos: Opera in Portugal in the Eighteenth Century (Cambridge, 1989), pág. 91.

53. ADMS, Leg. 2368, Duquesa de Medina Sidonia al Duque, 8 de agosto de 1767.

54. ADMS, Leg. 2368, Pedro Santamant al Duque de Medina Sidonia, 18 de noviembre de 1767.

55. ADMS, Leg. 2368, Soler al Duque de Medina Sidonia, 25 de noviembre de 1767. 
Un mes después, el 21 de diciembre de 1767, Soler escribió de nuevo al duque, pidiéndole el regreso de Santamant, esta vez con una amenaza encubierta, y también pidiéndole otro favor:

«S.r Deseo â V. E. alegres, y festivos Pasquas del Nac ${ }^{\text {to }}$ de Nuestro Redemtór, con toda la Posibilidad de Dones Espirituales, y temporales. en compañia de su amada Parienta, que asis me las prometo mui felizes.

Dos Cartas me tiene escritas Perico para que suplique â V. E. se digne de parte venir, hasta la Primavera, para cuio tiempo, no resfriandoseme el ánimo, pienso ir â visitár a $\mathrm{N}^{\text {tra }}$ $S^{\text {ra }}$ de Monsserrate. Verdaderam. ${ }^{\text {te }} S^{\mathrm{r}}$ el chico Lo necessita, si ha de llamarse Discipulo mio.

Participó â V. E. como he trabajado un Motete para el Concierto Espirituál de Paris, y no lleva mas recomendacion, que la misma obra, y aunque no pienso en llevarme el Premio, por falta de Hombre, con todo espero en Dios, no dejará de dár algun lustre a nuestra España. V. E. podrá mui bien sabér si el hijo del Ex ${ }^{\text {mo }} S .{ }^{r}$ embajador de francia el $S^{\mathrm{r}}$ Conde De Ossuna Se ha remitido ô no; y hazér, que me conste que ha llegado alla, que mas adelante sabremos de su merito; bien contemplo que su estilo es tan otro del que nosotros tenemos, que me temo nos hagan â puro premio, entrár en el suio.» ${ }^{56}$

El truco de emparejar la amenaza a Perico como su discípulo (que podría haber puesto en peligro sus perspectivas futuras) con el llamamiento al patriotismo del duque tuvo éxito. El duque replicó el 29 de diciembre:

«... El chico se le embiaré á V. R. antes de Quaresma, pues deseo que sin verguenza pueda llamarse siempre su discípulo.

Creo muy bien que el Motete q. ${ }^{\mathrm{e}} \mathrm{V}$. R. ha trabajado.$^{\mathrm{a}}{ }^{\mathrm{a}}$ Remitir â Paris, dará honor a ntâ España entre los sujetos habiles que nunca faltan en aquel gran Theatro a unq. ${ }^{\mathrm{e}}$ el estrag. ${ }^{\text {do }}$ gusto de los comunes profesores no pueda percivir ni admirar en el sus perfecciones.» $^{57}$

Desafortunadamente, faltan de los archivos de los Duques de Medina Sidonia todos los legajos del año 1768, el año después de la expulsión de los jesuitas de España. Pedro Santamant permaneció en El Escorial por lo menos parte del año ya que su Regina coeli para 8 voces, cuerdas y trompetas aparece en el catálogo de los archivos musicales de El Escorial con la nota «compuesta en el año de $1768 .{ }^{58}$ Por la carta de Soler del 17 de abril de 1768 al padre Martini de Bologna sabemos que había estado enfermo con «la maligna febre» pero planeaba visitar Montserrat. ${ }^{59}$ El 11 de julio José de Nebra, «maestro de clavicordio» del Infante Don Gabriel, murió, ${ }^{60}$

56. ADMS, Leg. 2368, Soler al Duque de Medina Sidonia, 21 de diciembre de 1767.

57. ADMS, Leg. 2368, Duque de Medina Sidonia a Soler, 29 de diciembre de 1767. Según Pierre, Constant: Histoire du Concert Spirituel, 1725-1790 (Paris, 1975), ninguna obra de Soler fue interpretada nunca.

58. Rubio, Samuel y Sierra, José: Catálogo del Archivo de Música de San Lorenzo el Real de El Escorial, (Cuenca, 1976), pág. 464.

59. KaSTner, Carta IV, pág. 239.

60. Solar-QuinTES, N.: «El compositor español José de Nebra (m. 1-VII-1768): nuevas aportaciones para su biografía», Anuario Musical, 9 (1954), pág. 202. 
comenzando el nombramiento de Soler como su sucesor durante dos meses al año cuando vino la corte a El Escorial. La Gaceta de Madrid de 23 de febrero de 1768 (pág. 68) anunció el nombramiento del Duque de Medina Sidonia como caballerizo mayor del rey Carlos III. También durante 1768 el duque publicó su traducción de la tragedia de Racine, Iphigénie en Aulide, como resultado fue hecho miembro de la Real Academia Española.

La única carta de Soler ai duque en 1769 fue fechada el 29 de diciembre. En ella reprendía al duque por no enviar un regalo de Navidad. Soler envió al duque turrón, manzanas y bizcochos:

«Señor: Supla V. E. â mi buen afecto, la molestia de mis toscas cartas; y la falta del Aguinaldo pobre, a los fieros Prados, $\mathrm{q}^{\mathrm{e}}$ no coadjuvan sinó con bellota, para Javalis, venados \&c. Por sobra de ocupacion y falta de Proporción, no pude en la parada remitir â V. E. una pequeña expresion de mi obligado reconocimiento, y assi lo hago ahora, remitiendo, en un cajoncillo 6 libras de turrón fabricado aqui, que dicen no hai semejante, me alegraré sea del agrado de V. E. tambien vá una cestita, $q^{\mathrm{e}}$ no he encontrado otra ni maior, ni menór, llena de camuesa, ô manzanas, con unos tarugos, ô bollos, $\mathrm{q}^{\mathrm{e}}$ en qualquier tiempo caldeandolos algo, ablandan la dureza, $q^{\mathrm{e}}$ demuestran. No quiero molestar mas a V. E. dar de satisfaciones de mi amor, $\mathrm{q}^{\mathrm{e}}$ me obliga â cumplir con tales frioleras, y no puede como quisiera: Dios me le conserve, y guarde como se lo $\operatorname{supp}^{\underline{\underline{c o}}} .{ }^{61}$

No hay mención de Perico Santamant que debía tener unos 17 años, la misma edad que el infante Don Gabriel, ahora el discípulo de Soler en El Escorial durante octubre y noviembre.

El año siguiente Soler escribió, una vez más, una sola carta al duque enviado saludos navideños y algunos regalos de turrón y vino:

«S. ${ }^{r}$ no he podido antes de haora anunciar â V. E. las felizes Pasquas del Nacim. ${ }^{\text {to }}$ de ntrô Redemptor las $q^{\mathrm{e}}$ deseo á V. E. mui cumplidas de salud, y gracia del S. ${ }^{\mathrm{r}}$ y para manifestár á V. E. mi buen afecto remito, una botella de Vino del $S^{\text {to }}$ de dos años, y 3 libras de turrón, para acabar de comér, y acordarse de quien le Ama.

Por carta de Cataluña de 13 del corriente sé, q e está enbotada la Malvasia de Sitjas, y $\mathrm{q}^{\mathrm{e}}$ estaria en camino á la primera ocasion; no ha venido antes, por $\mathrm{q}^{\mathrm{e}}$ la Gente del Norte han arrancados todos los generos de vinos, y Aguadiente, $q^{e}$ han podido con mucha priesa, lo $q^{e}$ he sentido por no ver cumplido el deseo tenia de $q^{e} V$. E. tuviese para estas Navidades una cosa particular Vino del $S^{\text {to }}$ Añejo no he encontrado más, V. E. perdone la cortedad, y reciba sobre todo Cariñoso afecto, $\mathrm{q}^{\mathrm{e}}$ aunq ${ }^{\mathrm{e}}$ se despide del Escoriál, sin despedirse de fr. Ant $^{\circ}$, fr. Ant ${ }^{\underline{o}}$ corresponde desidiendose de todas los Amigos menos de V. E. de quien jamás se despedirá.

[Al margen:]

Por falta de cubeto no vino la malvasia, pues los Artifices, no quieran fabricár cubetos chicos, Y esto quise significár con la Priesa de la Gente Nordeste.» ${ }^{62}$

61. ADMS, Leg. 2372, Soler al Duque de Medina Sidonia, 29 de diciembre de 1769.

62. ADMS, Leg. 2376, Soler al Duque de Medina Sidonia, 26 de diciembre de 1770. 
El 13 de enero de 1771, Soler escribió agradeciendo al duque los regalos de Navidad. De repente, el tono de la carta de Soler era de enfado:

«S: agradezco, estimo, y doi gracias â V. E. por averme expresado nuevam ${ }^{\text {te }}$ su cariño, con el regalo de $4 \mathrm{Lib}^{\mathrm{s}}$ de tabaco en dos Latas quadradas, 6 pañuelos de seda, y una arroba de chocolate, y aunque no era necesaria esta recordación, para el afecto q siempre he proffessado á V. E. con todo me estimúla, a que continue con nuevo fervór á pedir por la salud de su Alma, y Cuerpo, $\mathrm{q}^{\mathrm{e}}$ ya profesaba esta memoria en mis Sacrificios quotidianos, como por costumbre: asegurese V. E. q assi lo hago.

Supp ${ }^{\underline{c o}}$ a V. E. se digne entregár á Perico esta esquela (y perdone V. E. el atrevimon $\mathrm{q}^{\mathrm{e}}$ me precisa el hazerlo assi, para $\mathrm{q}^{\mathrm{e}}$ no alegue Escusa, de no aver recibido la mia) pues me tiene descabalado un $\mathrm{Lib}^{\mathrm{o}}$ de 40 Sonatas con quatro quadernos, $\mathrm{q}^{\mathrm{e}}$ serme llevo, y no puedo enquadernarle, por su desidia: lo peor es $S:^{r}$ que uno se me llevó los Originales, Perico las copias, y yo no me acuerdo de tales sonatas, con $\operatorname{loq}^{\mathrm{e}}$ vengo a quedarme sin nada.» ${ }^{63}$

La carta trae recuerdos de la primera carta de Soler al duque en 1761: una petición de un retorno del regalo de un «Libro de Clavicordio». La primera vez, el pretexto de Soler era haberlas copiado para llevarlas al monasterio de Montserrat. Esta vez, «uno se me llevó los Originales.» ¿Quién? ¿El Infante Don Gabriel ${ }^{64}$ Pero Perico «se me llevó... las copias» de las sonatas y no ha respondido a la carta de Soler.

Cinco días más tarde Soler escribió de nuevo, quejándose más de Perico:

«Ex ${ }^{\underline{m o}} \mathrm{~S}:{ }^{r}$ Doi a V. E. las gracias de aver echo escrivir á Perico, y aunq ${ }^{\mathrm{e}}$ me responde con dos Pliegos, no toca palabra de devolverme Los quadernos del Lib. ${ }^{\circ}$ los que me han sido la causa de mi sentida carta, pues á no aver sido este motivo, no le huviera escrito, pues ya me tiene enseñado á no ver letra suia en todo un año. Conozco que de su Resp ${ }^{\text {ta }}$ sola La Letra es suia, mas no las clausulas, pues no se le alcanza tanta Sonoridad.

Estrano mucho, $\mathrm{q}^{\mathrm{e}}$ solas sus cartas se me extravian, y no sucede esto, con las $\mathrm{q}^{\mathrm{e}}$ me escriven de Portugál, Bolonia, Cataluña \&c. Nunca ha gustado de mi, porq ${ }^{\mathrm{e}}$ le digo las verdades: en fin $S:^{r}$ le conosco como si le huviera parido y le he querido mas, $q^{\mathrm{e}}$ si me fuera hijo: Dios le hago un $S^{\text {to }}$, y le asista; $q^{\mathrm{e}}$ no quiero molestár á V. E. mas en este assumpto.

[Al margen:]

No se moleste V. E. en escrivirme, pues me parto mañana por la mañana a la villa del Orcajo, ha hazer unas pruevas de un muchacho $\mathrm{q}^{\mathrm{e}}$ pretende entrár en este Seminario.» ${ }^{65}$

El 24 de febrero de 1771, Soler escribió al duque dando noticias de su regreso al monasterio y «el arribo de la Malvasia de Sitjas [Sitges]». No hay mención de Perico o las copias de las sonatas.

63. ADMS, Leg. 2380, Soler al Duque de Medina Sidonia, 13 de enero de 1771.

64. Soler dio 27 sonatas para clave a Viscount Fitzwilliam el 14 de febrero de 1772 . Véase KIRKPATRICK, pág. 124.

65. ADMS, Leg. 2380, Soler al Duque de Medina Sidonia, 18 de enero de 1771. 
«Señor: con grandissimo gusto pongo en noticia de V. E. mi restablecim ${ }^{\text {to }}$ en esta Su celda, tanto por poderme ofrecér de nuevo á Su ordenes, como por participarle el arribo de la Malvasia de Sitjas á Su casa, la que me alegraré sea nada mas, que igual a mi deseo, este pongo á los pies de V. E. para $\mathrm{q}^{\mathrm{e}}$ siempre obedezca, como es debido.» ${ }^{66}$

El secretario del duque respondió brevemente a la carta de Soler «en ausencia del Duque y con su noticia... diciendo estimamos mucho su atencion en el Regalo de la Malvasia», el 27 de febrero de $1771 .^{67}$

Seis semanas después Soler aún no había recibido las sonatas pedidas. De nuevo escribió una carta al duque en tono enfadado, exigiendo que el duque ordenase a Perico que devolviera las sonatas. Además explicó el motivo didáctico de las sonatas.

«Señor: Aunque siento en el Alma molestár á V. E. con cartas, por cuio motivo solas las de Politica, y oblig. ${ }^{\mathrm{n}}$ de mi Cariño envio, ahora me precisa suplicár á V. E. se digne hazér, que Perico me remita Las Sonatas de mi Libro, que por Navidades envié a pedir, pues creo, que hasta tanto, que V. E. interpongo su Authoridad me tendré un Lib ${ }^{\circ}$ descabalado, cuio Lib $^{\circ}$ es para Estudiar las mas habiles, y de estos no habrá muchos, que le toquen todo, y por fin nada pido, en pedir los sudores de mi cara: Es quanto se me ofrece,

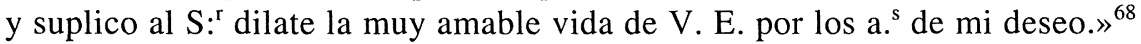

Otra vez, el secretario del duque respondió al Soler que «he reciv. ${ }^{\text {do }}$ la inclusa p. ${ }^{\text {a }}$ Santamant que he encaminado al Duque a fin segue se la haya cumplir.» ${ }^{69}$ El duque estaba con la corte en Aranjuez.

El 11 de abril Soler escribió a la Duquesa de Medina Sidonia, pidiéndole que mediase con «su poderosa autoridad» con el duque tocante a Perico:

«S $\mathrm{S}^{\text {ra }}$ Con todo mi caritativo affecto, supplico á V. E. se digne interponér su poderosa authoridád a fin de que el S. ${ }^{r}$ Duque no haga, ni proceda en cosa alguna contra Perico Santamánt, pues bastante es mi Carta, y espero en el S.r., que aunque sus pocos años no le dejan conocér, lo mucho que me dehe, mas adelante lo conocerá. Es fabór que espero recivir de V. E. por cuia vida ruego al $S^{\mathrm{r}}$ la conserve los a. ${ }^{\mathrm{s}}$ de mi deseo.» ${ }^{70}$

La estratagema de Soler funcionó. Escribió a la duquesa una semana después, triunfante de la devolución de las copias de las sonatas y sarcástico tocante a « $\mathrm{D}^{\mathrm{n}}$ Pedro Santamánt:»

«Señora: reciví Las Sonatas, que me tenia $\mathrm{D}^{\mathrm{n}}$ Pedro Santamánt desde Los principios de la Jornada passada, de cuio favór doi á V. E. mil g. ${ }^{\mathrm{s}}$, y la Sup ${ }^{\underline{c o}}$ no perdone. ocasiones en que yo pueda servir a V. E., pues deseo agradecido correspondér al grande affecto, que assi á V. E. como al $\mathrm{S}^{\mathrm{r}}$ Duque debo. $\mathrm{Nt}^{\mathrm{ro}} \mathrm{S}^{\mathrm{r}}$ prospere La amabilissima vida de V. E. Los muchos la deseo.

66. ADMS, Leg. 2380, Soler al Duque de Medina Sidonia, 24 de febrero de 1771.

67. ADMS, Leg. 2380, Santiago Sáez a Soler, 27 de febrero de 1771. Borrador escrito al margen del núm. 66.

68. ADMS, Leg. 2380, Soler al Duque de Medina Sidonia, 6 de abril de 1771.

69. ADMS, Leg. 2380, Santiago Sáez a Soler, 9 de abril de 1771. Al margen del núm. 68.

70. ADMS, Leg. 2380, Soler a la Duquesa de Medina Sidonia, 14 de abril de 1771. 
[Al margen:] Perdone V. E. el que incluia la carta de $\mathrm{D}^{\mathrm{n}}$ Pedro, que no se otro modo, pues las que no van assi seguras, me dice que no las recive.» ${ }^{71}$

En 1771 Pedro Santamant debería tener unos 19 años. Su nombre no aparece más en los archivos de Medina Sidonia pero antes de noviembre de 1776 «Señor Santaman» compuso «seis trios» para el cuñado del Duque de Medina Sidonia, el duodécimo Duque de Alba, cuya amplia biblioteca de música de cámara fue inventariada después de su muerte. En la tasación de la música e instrumentos que seguían al inventario las composiciones de Santamant aparecen como «seis divertimientos por Santaman [valorados] en 30 reales.» ${ }^{72}$

El altercado acerca de las sonatas de Soler acabó con la correspondencia entre Soler y el duque. Soler escribió una carta más a la duquesa dos años después, el 31 de enero de 1773, en la cual se refirió al distanciamiento entre el duque y él mismo:

«Señora: no obstante, $\mathrm{q}^{\mathrm{e}}$ considero no ignorará V. E. $\mathrm{q}^{\mathrm{e}}$ â ntrô Rev ${ }^{\underline{m o}}$ P. Prior fr. Bernardo Lorca el Rey he eligió por Obispo de Guardis, y nombró por Prior de Esta al Rev $\mathrm{p}^{\mathrm{e}}$ fr. Julián Villegas, con todo se lo prevengo â V. E. si ha de entrár en esta el chico q. ${ }^{\mathrm{e}}$ V. E. me Sup ${ }^{\underline{c o}}$ en la Jornada passada paraq ${ }^{\mathrm{e}}$ V. E. esponga â este nuevo Prior como el passado concedió esta gracia â V. E. de lo q no estoi ignorante yo, y añadía V. E. q era util, y quedamos en $\mathrm{q}^{\mathrm{e}}$ por Abril seria admitido.

Con esta ocasión de esta carta, no quiero pasár en silencio y descubrir â V. E. un terrible pensamiento $\mathrm{q}^{\mathrm{e}}$ aun en el $\mathrm{S}^{\mathrm{t} o}$ Sacrificio de La Missa me persigue, y es, $\mathrm{q}^{\mathrm{e}}$ ya tengo habito echo todos los dias en el Memº de vivos de acordarme de Rogár â Dios assi por la salud de V. E. como por la del Duque mi S.r., en recompensa de los muchos beneficios, $\mathrm{q}^{\mathrm{e}}$ tengo recividos de las misericordiosas entrañas de V. E. y el S. ${ }^{r}$ Duque todas los años, y Es que rimentando en el presente, $\mathrm{q}^{\mathrm{e}}$ no solo no ha llegado â mi mano el alivio acostumbrado, mas ni aun de mi pequeña y agradecido recordación, una pequeña Escuela siquiera de sér bien recivida, me tiene quasi asegurado de tenér alguna sospecha de mi cariño; yo confieso, ignoro en $\mathrm{q}^{\mathrm{e}}$ puedo averles dado en $\mathrm{q}^{\mathrm{e}}$ funden queja contra mi por tanto Supp $\underline{\underline{c o}} \hat{\mathrm{a}}$ V. E. me segua de Este cuidado por los clavos de Jesus, $q^{\mathrm{e}}$ mientras yo viva siempre seré un pregonero agradecido, y oblibligado â Publicár sus misericordiosas entrañas, y â Satisfacér el mucho bien $\mathrm{q}^{\mathrm{e}}$ â mi me tienen echo.» ${ }^{73}$

No hubo respuesta por parte de la duquesa.

En la primavera de 1773 el duque viajó con la corte a Aranjuez donde consiguió su mayor éxito con las parejas, «una especie de baile a caballo». ${ }^{74} \mathrm{El}$ evento fue conmemorado en una pin-

71. ADMS, Leg. 2380, Soler a la Duquesa de Medina Sidonia, 17 de abril de 1771.

72. ADMS, Leg. 5788, «Inventario y Tasación de los Instrum. ${ }^{\text {tos }}$ y Papeles de Música de la Testamentaria del Exmo. S. $D^{n}$ Fern. ${ }^{\text {do }}$ de Silba y Albarez de Toledo, Duque que fue de Alba. Madrid á 20 de Marzo de 1777». Véase Hollis, George Truett: «Musical Patronage in Eighteenth Century Spain: The Music Library and Music Instrument Collection of the XII Duke of Alba (d. 1776)», Revista de Musicología, XVI (1993) núm. 6, págs. 3476-3481.

73. ADMS, Leg. 2388, Soler a la Duquesa de Medina Sidonia, 31 de enero de 1773.

74. Swinburne, pág. 348: «These Parejas are a kind of dance on horseback, in imitation, perhaps of the Trojan games... They parade with music before them in a large tilting yard near the palace [in Aranjuez]; separate themselves into detachments, and perform various intricate figures, resembling those of a stage dance.» 
tura al óleo de Luis Paret y Alcázar titulada Las parejas reales, actualmente en el Museo del Prado de Madrid. ${ }^{75}$ Representa al Príncipe de Asturias, al Infante Don Gabriel, al Infante Don Luis Antonio, y al Duque de Medina Sidonia, cada uno encabezando un escuadrón de doce nobles vestidos a la antigua usanza española y a caballo:

«La última cuadrilla, con trajes y arreos blancos y dorados, traía al frente D. Pedro Alonso Pérez de Guzmán el Bueno, decimocuarto Duque de Medinasidonia y Caballerizo mayor del Rey. Era Medinasidonia de los grandes señores éclairés de la época, entusiasta de las nuevas ideas, y protector de las Letras, que cultivó él mismo, traduciendo, no sin ayuda, varias obras del francés, entre las cuales contaban La Ifigenia y El Agamenón, de Racine, y el Hernán Cortés, de Pirón... Fue Medinasidonia miembro de la Real Academia Española y de la de Ciencias de Londres, y protegió mucho a los sabios y eruditos de su tiempo, D. Andrés de Barcia, Fray Juan de la Concepción, D. Diego de Torres, el Maestro Fr. Enrique Flórez y el Maestro Fr. Martín Sarmiento, habiendo recogido los manuscritos de este último y hecho sacar copia de ellos, que componen diecinueve tomos en folio...» ${ }^{76}$

Un poco después, en el mismo año, el duque recibió la Real Distinguida Orden Española de Carlos III. En agosto de 1773 el duque viajó a Toledo por el funeral de su tío paterno, el Arce-

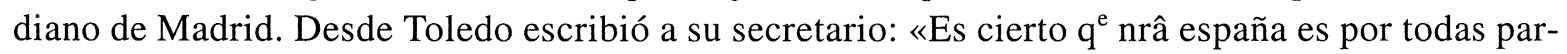
tes Rica; y miserable.» ${ }^{77}$

Cinco años y medio después el Duque de Medina Sidonia murió durante un viaje a París, que él emprendió tras la muerte de su esposa debida a un cáncer de pecho, ocurrida unos meses antes, en $1778 .^{78}$ El duque murió el 6 de enero de 1779 de apoplejía, antes de llegar a Barcelona, cerca de Vilafranca del Penedés, en una posada del camino, la «Venta de los Monges», rodeado de lacayos y muleteros. ${ }^{79}$ El último descendiente directo de Guzmán el Bueno tenía 54 años.

Sobre los últimos años del padre Soler, uno debe volver primeramente a su necrología en las Memorias sepulcrales:

«... mereció dar lección de clave al serenísimo señor infante don Gabriel todas las jornadas que vino la corte a esta real casa; y le compuso a $\mathrm{S}$. A. mucha música especial [...] Llegó a tener treinta y un años de hábito, que es bastante respecto de tanto encierro y estudio de día y de noche, [...] Por último se le fue aumentado la calenturilla que hacia más de un mes le había predido, y a esto se le siguió una fatiga muy grande en el pecho. [...] Esto procedía, como llevo dicho, de su genio compasivo y dócil, y de parecerle eran muchas cosas injustas las que sentía en su corazón, como si fueron contra su misma persona [...] Fue su tránsito a 20 de diciembre de $1783 .{ }^{80}$

Él también tenía 54 años.

75. López Serrano, Matilde: Las Parejas / Juego Hípico del siglo XVIII (Madrid, 1987), pág. 60, nota 7.

76. Coloma, Luis: Retratos de antaño (Madrid, 1895), c. XII, págs. 225-246; citado en LóPEZ SerRano, págs. 39-40.

77. ADMS, Leg. 2388, Duque de Medina Sidonia a Santiago Sáez, 23 de agosto de 1773.

78. Blanco Soler, C.: La Duquesa de Alba y su tiempo (Madrid, 1949), pág. 74, nota 29.

79. Gaceta de Madrid, 19 de enero de 1779, pág. 51; Coloma, pág. 244.

80. Memorias sepulcrales, ff. 294v-296r. 
La correspondencia entre el padre Soler y el Duque de Medina Sidonia ofrece nueva información para la biografía de Soler. Además revela el carácter didáctico de algunas de sus sonatas, aquellas que formaron el Libro de 40 sonatas de 1770 . Puede ayudar a datar las sonatas de Soler y también a aclarar el «misterio» que rodea la $\mathrm{G}$ alta de los clavicordios españoles del siglo XVIII.

Pero lo más importante de esta correspondencia es que nos permite vislumbrar el «carácter personal y musical» de Soler que Klaus Heimes echó de menos en la necrología. Demuestra que Soler era avaricioso, egoísta, ambicioso, sarcástico, desviado y manipulante. De hecho, la correspondencia humaniza a Soler.

Ahora se puede entender mejor qué quiere decir cuando Soler escribió al Duque de Medina Sidonia en enero de 1764, después de recibir el primer regalo de Navidad del duque:
«Quasí cinco horas â Solas
desbuché alegres Sonatas,
repitiendo las pedidas,
por Vocencia, vezes tantas.»

El padre fray Antonio Soler no fue sólo el piadoso fraile de El Escorial; fue también, como él escribió sobre sí mismo, «el Diablo vestido de fraile.»

\section{ADDENDUM I}

(El texto completo de Carta $\mathrm{n}^{\circ} 2$ de Soler)

\author{
$\mathrm{Ex}^{\mathrm{mo}} \mathrm{S} .^{\mathrm{r}}$ \\ $\mathrm{S}^{\mathrm{r}}$ : con licencia, vaia un \\ ROMANZE \\ De un Grande voi â contar \\ las proezas, que me pasan, \\ pues me vino de Su Mano \\ un Bote como una casa. \\ Es Grande, y no merecido, \\ que duplica su Bonanza, \\ pero todo esto granjea, \\ quien â todo un Duque arrastra. \\ Quasí cinco horas â Solas \\ desbuché alegres Sonatas, \\ repitiendo las pedidas, \\ por Vocencia, vezes tantas. \\ No pude de otra manera \\ celébrar la tal llegada \\ del Bote, a quien es tripé \\ para verle las Entrañas. \\ Seis Libras? Ô que prodigio! \\ Y de miga tan Estraña,
}

que al gustarle prorrumpí, Este, Duque, Es de la Avana. Vease como que daron los Reyes Magos â Espadas, pues al Niño no le dieron para un Bote ni una Blanca. Otros Magos me vinieron haziendo me dos mil Salvas, todo era para adorár al que Vocencia Regala. [p. $1^{\vee}$ ] Que maladita adoracion dan los bellacos, con Capa de amistad, que es lo peór pues â cada paso matan. Son tantos los Pretendientes, que no alcanzára la Lata, Si sirviera â los Amigos, quien con Libras, quien â Capas. Con quien pueda, ya me escúso, con quien nó, me muele, y mata, pero protesto, que â otra, no tengo de hablar palabra. Esto se hallan con ser buenas 
las tripas de la cavalla, que como Gitanos corren tras ellas, para arrancarlas.

Recibile, ya lo dixe pero no dixera nada, si vendido no dixera,

Que â Vocencia doi mil gracias. Doi fin con el Grande gusto de unas Dezimas forzadas â la firma de Vocencia, que serán como de mi Alma

$$
1 .^{a}
$$

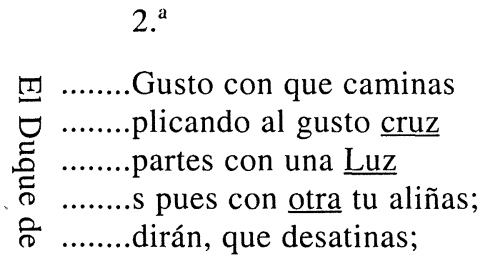

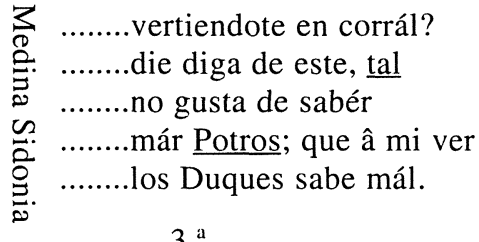

$$
\begin{array}{cc}
\multicolumn{1}{c}{3 .^{a}} \\
\\
\text { [p. }
\end{array}
$$

\section{AdDENDUM II}

\section{(El texto completo de Carta $\mathrm{n}^{\circ} 3$ de Soler)}

$E x^{m o} S^{r}$

$S^{r}$ : Vaia en Octavas.

$$
1 .^{\mathrm{a}}
$$

Duque aunque ocupado estoi con las Pascuas en mil cosas, por sér tiempo de jocosas coplas, escrivo estas oy: Yo no se si al blanco doi, ô en la erradura daré, Solo decirte sabré Sepas ya, $\mathrm{q}^{\mathrm{e}}$ tuio soi. $2 .{ }^{\mathrm{a}}$

Voi â dár Duque y Señor Pascuas con la viuda mula, que sinó come es por Bula, sinó dispara es de Amór $Y$ al vér, que su criadór en su albergue se aposenta Está loca de contenta, pues se libra de un Doctor. 
$3 .^{\mathrm{a}}$

Aunques facíl el entrár dando Pascuas en Romance antes, que el Buey quiera, lance, del Portál he de escapár, no sea quiera provár aqueste gran Cavallero sus Plumas en mi tintero si las podrá Remojár.
$4 .^{a}$

En Romance he de plantár con imitación precisa de aquél que inventó la Missa, Y la quiso celebrár:

[p. 1 ${ }^{v}$ Nome lleguen â apurár, si tendré ô no barro a manos pues con los quatro Escrivanos sobra tela, que cortár.

\section{Romance de la vida de Christo, en imitación de La Missa.}

Oigame el Duque mi Amigo si piensa vivo olvidado, que â Banderas descubiertas, sacaré al Niño los trapos.

El Salmista dixo, que es

Sacerdote señalado bien se vió, pues que en su Missa gastó tres dias de espacio. El Introito en un huerto con ministros el Malvado del Sacristán Judas quiso en páz de Amigo entonarlo. Siguió el cordero después atado de pies, y manos

Y apenas amaneció fué de Herodes â Pilatos. Solfeár quiso la Capilla pero tan descompasados, que los Kiries de su Missa â espaldas ha de Llevarlos. La Gloria ya le cantó otro tiempo adelantado, El cielo en su Nacimiento, $\mathrm{Y}$ así pudieron deparlo. Las oraciones primeras de rodillas las echaron mientras unos entonaban otros le ivan solfeando. Rey de los Judios Ave proseguian los Malvados $Y$ en verdád, que le cantaban el Evangelio de Plano. Prosiguiendo pues su tema intentaron coronarlo, y eligieron tal corona, que sus sienes traspasaron. De Púrpura le vistieron por maiór mofa, y escarnio, y al llegár al ofertorio

Lavó Pilatos sus manos.

Despues, que ofrecieron todos

Su Sangre, y de sus hijastros:

mando luego, que tocáran este Presidente â Sanctus. Pilatos quiso asentarse por vér, que íva tan despacio el celebrante en su Missa, Y los ministros rabiando. Pidió el tintero, y la Pluma,

Y al que confessó inculpado Sentenció â muerte, por que de la Missa siga el Canon. Salió en fin de aquel Pretorio como casa de Pilatos, Y aunque Librarle inventó en fin Salió bien cargado. Empezaron los Mementos por las calles pregonando, que si haora son silenciosos entonces fueron voceados. Ya llegó â punto de alzár Y por sér manifestado, al instante se dexó clavár de sus pies, y manos, Alzaron, y tan de golpe dexaron los inhumanos caér aquel Rey del cielo, que el cuerpo desconiuntaron.[?] 
[p. 2']

Il Padre dá grandes vozes por sí está desamparado, $\mathrm{Y}$ en el memento de muertos La Alma le pone en sus manos. En la Sepultura estuvo Pater Noster, como humano, Y del Limbo respondieron Sed Libera nos â malo. La sumprión en esta Missa adelantada dexaron, mas las ultimas col-lectas Marias irán Llorando. Resuscitará â pesár de la furia de aquel Bárbaro Judaismo, y le oirán el Pax vobis vivo, y claro. Que hermosura celestiál verle ya Resuscitado, cantará Ite Missa est pues nos ve ia rescatados. $\mathrm{Y}$ agradeciendo nosostros Beneficios tan Sagrados, â este Redemtor, y triunfo Deo qratias le digamos.

Estas Pasquas Duque mio este Redemtór amado te conceda como quiero todos los dias del año. En las virtudes aumento, $Y$ en el vitalicio humano tál prosperidád sin tasa, que te cargue bien la Mano. Es la fecha en Diezinueve de Diziembre, que contamos, en San Lorenzo el Reál del año sesenta, y quatro.

\section{DEZIMA}

Antes, que el Sol Rompa hermoso, antes, que nueva Luz Rompa, $\mathrm{Y}$ antes, que venga con Pompa, Emanuél Niño gracioso, Quiero Duque, que amoroso Le tengas Tabaco este año, porque en los nidos de antaño (Segun llego â Colegir de este polvo) he de decir, que no hai Pajaros Ogaño. 


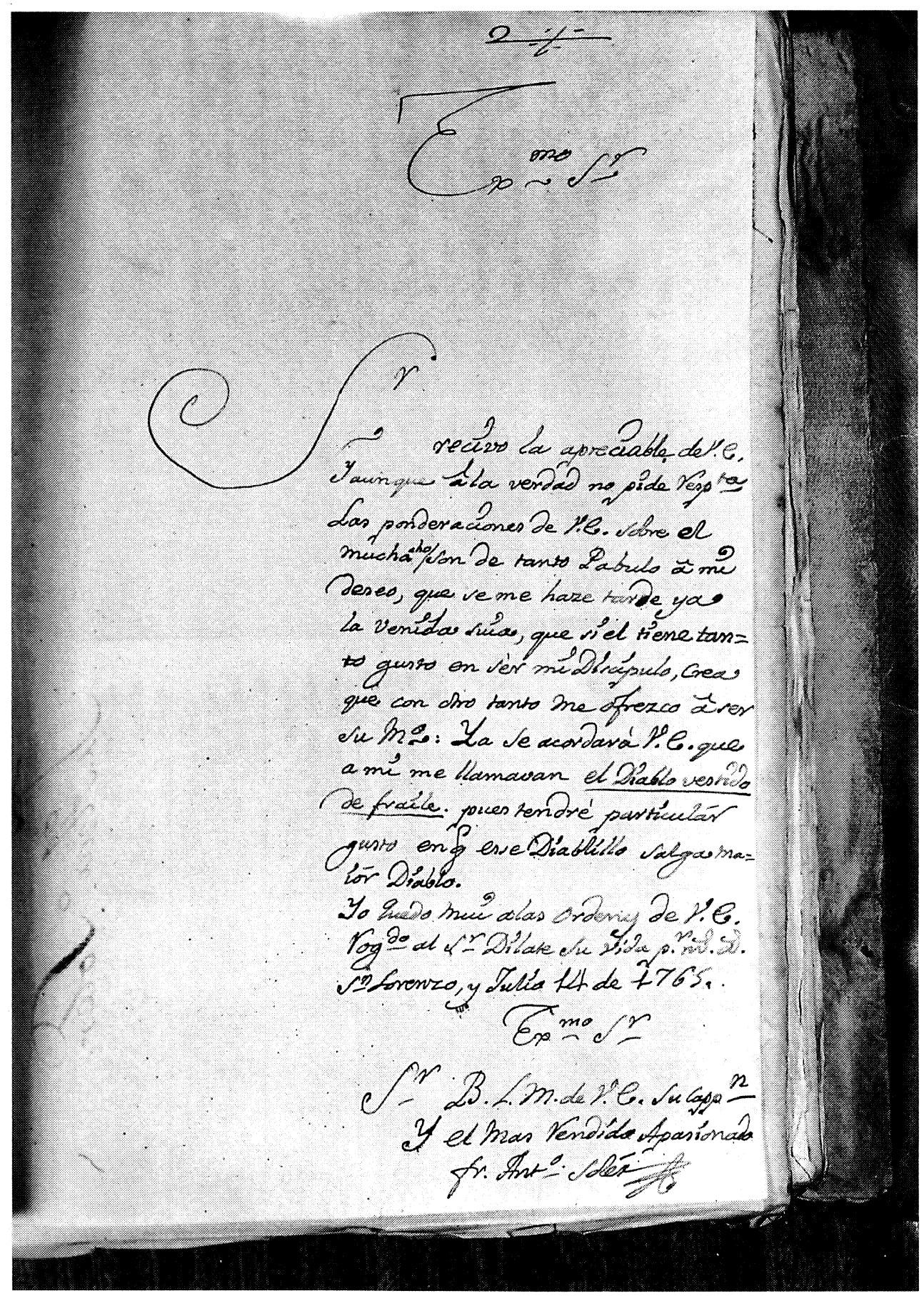

Carta del P. Antonio Soler (14 de julio de 1765) al duque de Medina Sidonia en la que afirma que le llamaban «el Diablo vestido de fraile». 